\title{
Synthesis, crystal structure and charge transport properties of one-electron oxidized zirconium diphthalocyanine, $\left[\mathrm{ZrPc}_{2}\right] \mathrm{IBr}_{2}$
}

\author{
Jan Janczak $^{\text {a,* }}$, Genivaldo J. Perpétuo ${ }^{\text {a,b }}$ \\ ${ }^{a}$ Institute of Low Temperature and Structure Research, Polish Academy of Sciences, Okolna 2, P.O. Box 1410, 50-950 Wroctaw, Poland \\ ${ }^{\mathrm{b}}$ Departamento de Física, Instituto de Ciências Exatas e Biológicas, Universidade Federal de Ouro Preto, 35400-000 Ouro Preto, MG, Brazil
}

Received 8 May 2006; accepted 4 June 2006

Available online 4 July 2006

\begin{abstract}
Crystals of the new one-electron oxidized zirconium diphthalocyanine, $\left[\mathrm{ZrPc}_{2}\right] \mathrm{IBr}_{2}\left(\mathrm{Pc}=\mathrm{C}_{32} \mathrm{H}_{16} \mathrm{~N}_{8}\right)$ were grown directly from phthalonitrile and pure zirconium powder under the oxidation conditions of $\mathrm{IBr}$ at $220^{\circ} \mathrm{C}$. $\left[\mathrm{ZrPc}_{2}\right] \mathrm{IBr}_{2}$ crystallises in the space group $P 2_{1} / m$ of the monoclinic system, with lattice parameters of: $a=6.697(1), b=25.483(5), c=16.918(3) \AA, \beta=100.03(3)^{\circ}$ and $Z=2$. The crystals of $\left[\mathrm{ZrPc}_{2}\right] \mathrm{IBr}_{2}$ are built up from one-electron oxidized $\left[\mathrm{ZrPc}_{2}\right]^{+}$units that form stacks parallel to a axis of the crystal and mixed electron-rich trihalide ions of $\mathrm{IBr}_{2}{ }^{-}$. The iodine atom of the $\mathrm{IBr}_{2}$ ions is located at the inversion center, so the $\mathrm{IBr}_{2}{ }^{-}$ions are linear and symmetrical. The mutual arrangement of $\left[\mathrm{ZrPc}_{2}\right]^{+}$and $\mathrm{IBr}_{2}{ }^{-}$ions is different to that found in the one-electron oxidized $\left[\mathrm{ZrPc}_{2}\right]_{3} \cdot \mathrm{I}_{2}$ complex as well as to that found in the tetragonal crystals of partially oxidized $\left[\mathrm{ZrPc}_{2}\right]\left(\mathrm{I}_{3}\right)_{2 / 3}$. EPR experiment shows that the oxidation of the diamagnetic $\mathrm{ZrPc}_{2}$ complex by $\mathrm{IBr}$ is ligand centered. The $\mathrm{UV}-\mathrm{Vis}$ spectrum of $\left[\mathrm{ZrPc}_{2}\right] \mathrm{IBr}_{2}$ shows, besides the bands observed in the spectrum of $\mathrm{ZrPc}_{2}$, one additional band at $\sim 496 \mathrm{~nm}$, which indicates the existence of the one-electron oxidized phthalocyaninato $(1-) \pi$-radical ligand and it is assigned to the electronic transition from a deeper level to the half-occupied HOMO level. The single-crystal electrical conductivity data shows anisotropy and non-metallic character in conductivity $(\mathrm{d} \sigma / \mathrm{d} T>0)$. The charge transport mainly proceeds along the stacks of one-electron oxidized $\left[\mathrm{ZrPc}_{2}\right]^{+}$units. The relatively high conductivity along the $\left[\mathrm{ZrPc}_{2}\right]^{+}$stack results from the staggered configuration of the Pc-rings (rotation angle $45.0(3)^{\circ}$ ) that makes short inter-ring $\mathrm{C}_{\alpha}($ pyrrole $)-\mathrm{C}_{\alpha}($ pyrrole) contacts (2.858(2)-3.017(3) А) and greatest overlap of the HOMO orbitals that form the conduction band of the molecular materials.
\end{abstract}

(C) 2006 Elsevier Ltd. All rights reserved.

Keywords: Zirconium diphthalocyanine; Partially oxidized diphthalocyanine; Crystal structure; Magnetic properties; Electrical conductivity

\section{Introduction}

Partial oxidation by iodine of phthalocyaninato-like metallomacrocyclic complexes has yielded a series of onedimensional highly conducting molecular materials [1-14]. Generally, the electrical properties of these materials are strictly connected with the structural and electronic features of the macrocyclic ring, which is the site of the extensive $\pi$ electron delocalisation, as well as on the nature and the electronic structure of the central metal ion [4]. The majority of the partially oxidized metallophthalocyaninato complexes crystallise in the tetragonal system and retain a single struc-

\footnotetext{
${ }^{*}$ Corresponding author. Tel.: +48 71343 5021; fax: +48 713441029.

E-mail address: j.janczak@int.pan.wroc.pl (J. Janczak).
}

tural motif that consists of metal-over-metal pseudo-monodimensional columnar stacks of partially oxidized $\mathrm{MPc}^{\delta+}$ units surrounded by linear chains of symmetrical triiodide anions [6]. The arrangement of the macrocycles in the stacks can be described by an ABAB pattern along the $c$ axis, with a rotation angle $\varphi$ between the adjacent A and B macrocycles. The interplanar spacing between the macrocycles within the stacks is not too different from the average value of $\sim 3.25 \AA$, i.e. half of the $c$ parameter of the crystals, which indicates a strong $\pi-\pi$ interaction between the macrocycles within the stacks $[15,16]$. The $\pi-\pi$ interaction between the partially oxidized macrocyclic rings is responsible for the observed high conductivity of these materials $[17,18]$.

An understanding of the charge transport in these partially oxidized macrocyclic molecular materials requires 
the knowledge of the 'ionicity', i.e. degree of the partial oxidation. Resonance Raman and ${ }^{129}$ I Mössbauer spectroscopies as well as diffuse $\mathrm{X}$-ray scattering techniques are simple means of characterising the anionic polyiodine species and determine the 'ionicity' [19-23]. On the other hand, EPR spectroscopy is useful for characterising the materials, if both parts of the complex, i.e. the central metal (for example $\mathrm{Mn}, \mathrm{Fe}, \mathrm{Co}$ ) and the $\pi$-electron macrocyclic ligand, are redox active since both oxidized forms $\mathrm{M}^{2+}\left(\mathrm{Pc}^{(1-)}\right) \mathrm{I}$ and $\mathrm{M}^{3+}\left(\mathrm{Pc}^{(2-)}\right) \mathrm{I}$ exhibit different EPR spectra. Additionally, EPR spectroscopy provides clear evidence for exchange coupling between the localised unpaired electron on the central metal ion and the $\pi$-carriers of the macrocycle within the stacks, as observed for CoPcI [24] and CuPcI [25], both linear-chain metal-spine conductors.

Although a few partially oxidized metallodiphthalocyaninato complexes are known [26], the correlation between the structure, $\pi$-orbital overlap and conductivity has not been systematically examined for such a system. In the course of our studies on metallodiphthalocyaninato complexes, the partially oxidized sandwich-type metallodiphthalocyanines are divided into two categories: (1) undoped metal(III) diphthalocyanines [27-32] and (2) iodine-doped partially oxidized metal(III) and metal(IV) diphthalocyanines [33-39]. In the first category $\mathrm{M}(\mathrm{III}) \mathrm{Pc}_{2}$, exhibiting semiconducting properties, the central metal $\mathrm{M}(\mathrm{III})$ is sandwiched between the $\mathrm{Pc}^{2-}$ and one-electron oxidized $\mathrm{Pc}^{-\cdot}$ radical ligand, however, the $\mathrm{X}$-ray single crystal analysis shows that both halves of these sandwich complexes are equivalent structurally, thus a non-integral oxidation state should be assigned to both of them $(\rho=-1.5)$. In the second category, iodine-doped metal(III) and metal(IV) diphthalocyanines, the conductivity depends strongly on the amount of iodine-doped atoms, which is closely correlated with the formal oxidation state of Pc macrocyclic ring.

Similar to iodine-doped metallomonophthalocyanines, the iodine-doped metallodiphthalocyaninato complexes also crystallise in the tetragonal system, in which the central metal ion is disordered over two symmetrically equivalent positions [33-39]. Quite recently we have stated that iodine-doped zirconium diphthalocyanine, depending on the crystallisation process and the amount of the iodine, can crystallise also in the monoclinic system [39]. Using a slightly modified method [40] we have obtained a new partially oxidized zirconium diphthalocyanine $\left[\mathrm{ZrPc}_{2}\right] \mathrm{IBr}_{2}$. Although, this complex contains the trihalide ions $\mathrm{IBr}_{2}^{-}$, similar to the tetragonal iodine doped zirconium diphthalocyanine $\left[\mathrm{ZrPc}_{2}\right]\left(\mathrm{I}_{3}\right)_{2 / 3}$ that contains the $\mathrm{I}_{3}{ }^{-}$ion [38], the complexes are not isostructural. Therefore for understanding the charge transport properties of $\left[\mathrm{ZrPc}_{2}\right] \mathrm{IBr}_{2}$ complex a knowledge of its crystal structure is needed. Additionally, the correlation between the crystal structures and charge transport properties of the two iodine-doped different zirconium diphthalocyaninato complexes $\left[\mathrm{ZrPc}_{2}\right]\left(\mathrm{I}_{3}\right)_{2 / 3}$, $\left[\mathrm{ZrPc}_{2}\right] \mathrm{I}_{3} \cdot \mathrm{I}_{2}$, described earlier $[38,39]$, with the third complex $\left[\mathrm{ZrPc}_{2}\right] \mathrm{IBr}_{2}$, described here, are reported. The crystal structures and properties of the partially oxidized zirconium diphthalocyanine complexes are discussed and compared with the undoped $\mathrm{ZrPc}_{2}$ complex [41].

\section{Experimental}

\subsection{Synthesis}

All reagents were of the highest grade commercially available and were used as received. The crystals of $\left[\mathrm{ZrPc}_{2}\right] \mathrm{IBr}_{2}$ were obtained directly by the reaction of pure powdered zirconium and phthalonitrile under a stream of IBr. The powdered zirconium $(0.182 \mathrm{~g})$, phthalonitrile $(2.050 \mathrm{~g})$ and $\operatorname{IBr}(0.450 \mathrm{~g})$ in a molar proportion of $1: 8: 2$, with about $5 \%$ excess of $\mathrm{IBr}$, were mixed together and pressed into pellets. The pellets were inserted into an evacuated glass ampoule (ca. $25 \mathrm{~cm}$ long) and sealed. The part of ampoule with the pellets was heated at about $220^{\circ} \mathrm{C}$ for one day. At this temperature the liquid phthalonitrile undergoes catalytic tetramerization forming the phthalocyaninato rings, which accepts the electron from the zirconium and forms sandwich $\mathrm{ZrPc}_{2}$ molecules. Simultaneously $\mathrm{IBr}$ partially oxidized the $\mathrm{ZrPc}_{2}$ molecules and transforms into $\mathrm{IBr}_{2}^{-}$ions and neutral diiodine molecules, yielding good quality single crystals with the composition $\left[\mathrm{ZrPc}_{2}\right] \mathrm{IBr}_{2}$. The major part of the iodine formed during formation of the $\left[\mathrm{ZrPc}_{2}\right] \mathrm{IBr}_{2}$ crystals resublimed at the cooler part of the ampoule. After opening the ampoule, the iodine that formed from $\mathrm{IBr}$ during the preparation procedure as an impurity is easily lost after expose to air at room temperature (3-4 days) or by slowly heating to about $40-45^{\circ} \mathrm{C}$. The elemental analysis has been performed on an energy dispersive spectrometer. Calc. for $\mathrm{C}_{64} \mathrm{H}_{32} \mathrm{~N}_{16} \mathrm{ZrIBr}_{2}$ : $\mathrm{Zr}$, 6.50; I, 9.04; Br, 11.38; C, 54.78; N, 15.96; H, 2.34. Found: $\mathrm{Zr}, 6.45 ; \mathrm{I}, 9.15 ; \mathrm{Br}, 11.33 ; \mathrm{C}, 54.84 ; \mathrm{N}, 15.98 ; \mathrm{H}, 2.29 \%$.

\subsection{X-ray diffraction study of $\left[\mathrm{ZrPc}_{2}\right] \mathrm{IBr}_{2}$}

The X-ray single crystal data were collected on a KUMA KM-4 diffractometer equipped with a two-dimensional area CCD detector from a single crystal (black-violet) with dimensions of $0.22 \times 0.18 \times 0.14 \mathrm{~mm}$. The graphite-monochromatized Mo K $\alpha$ radiation $(\lambda=0.71073 \AA)$ and $\omega$-scan technique with $\Delta \omega=0.75^{\circ}$ for one image were used. 960 images for six different runs covering over $95 \%$ of the Ewald sphere were performed. The exposure times were $20 \mathrm{~s} /$ image. Accurate cell parameters were refined by leastsquares methods on the basis of 2577 of the strongest reflections. One image was monitored as a standard after every 40 images for a control of the stability of the crystal. Integration of the intensities, corrections for Lorentz and polarisation effects were carried out using KUMA KM-4 CCD software [42]. Face-indexed analytical absorption was calculated using the SHELXTL program [43]. The minimum and maximum transmission factors are 0.641 and 0.744 , respectively. A total of 25532 (6899 independent, $R_{\text {int }}=$ 0.0306 ) reflections were integrated and used for the crystal 
structure determination. The structure was solved by the Patterson heavy atom method and refined by full-matrix least-squares method using the SHELXL97 program [44] with anisotropic thermal parameters for all non-hydrogen atoms. The hydrogen atoms of the benzene rings were introduced in their geometrical positions (HFIX 43) with isotropic thermal parameters $U_{\text {iso }}(\mathrm{H})=1.2 U_{\text {iso }}(\mathrm{C})$, i.e. $20 \%$ higher than the thermal parameters of the carbon atom directly bonded to the $\mathrm{H}$ atom. The final difference Fourier maps showed no peaks of chemically significance $(+0.335$ e $\AA^{-3}$ and -0.926 e $\AA^{-3}$ ). More details of data collection and final refinement parameters are listed in Table 1 and in the Supporting Information. Selected geometrical parameters are collected in Table 2.

\subsection{Raman spectroscopy}

The resonance Raman spectrum was recorded at room temperature on a Jobin-Yvon Ramanor U-1000 spectrom-

Table 1

Crystallographic data and final refinement parameters for $\left[\mathrm{ZrPc}_{2}\right] \mathrm{IBr}_{2}$

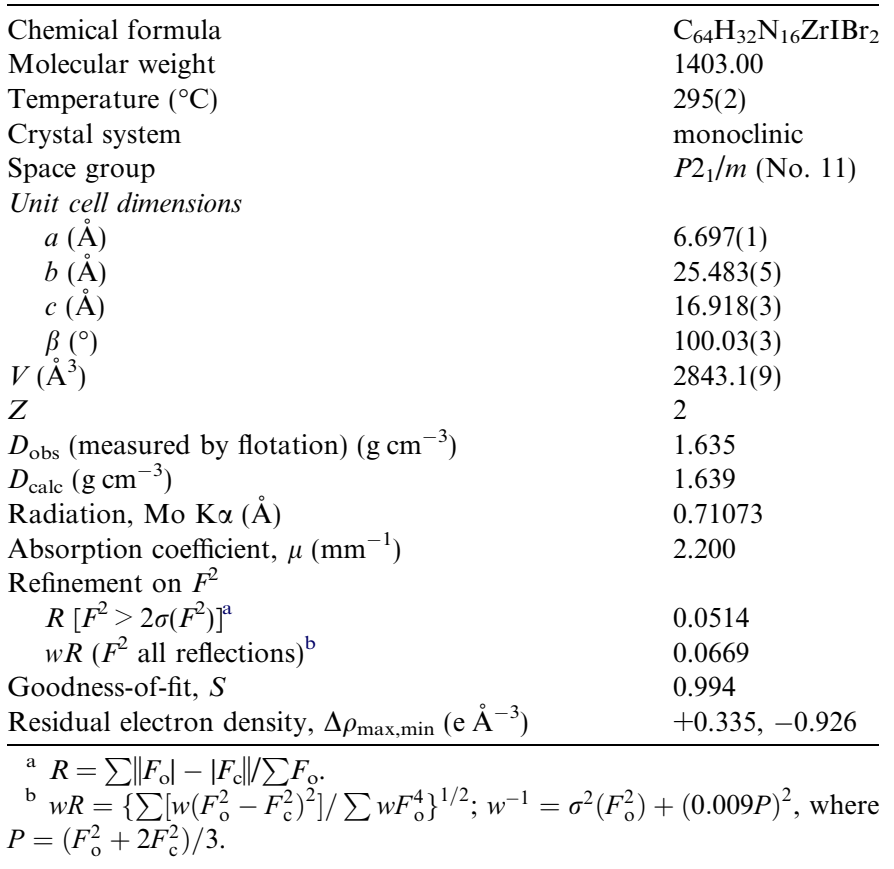

Table 2

Selected bond distances $(\AA)$ and angles $\left(^{\circ}\right)$ for $\left[\mathrm{ZrPc}_{2}\right] \mathrm{IBr}_{2}$

\begin{tabular}{lclr}
\hline $\mathrm{I} 1-\mathrm{Br} 1$ & $2.694(1)$ & $\mathrm{Zr}-\mathrm{N} 2$ & $2.377(4)$ \\
$\mathrm{Zr}-\mathrm{N} 4$ & $2.311(4)$ & $\mathrm{Zr}-\mathrm{N} 6$ & $2.287(6)$ \\
$\mathrm{Zr}-\mathrm{N} 8$ & $2.280(5)$ & $\mathrm{Zr}-\mathrm{N} 10$ & $2.283(6)$ \\
$\mathrm{N} 2-\mathrm{Zr}-\mathrm{N} 4$ & $74.8(2)$ & $\mathrm{N} 2-\mathrm{Zr}-\mathrm{N} 6$ & $76.7(2)$ \\
$\mathrm{N} 2-\mathrm{Zr}-\mathrm{N} 8$ & $75.8(2)$ & $\mathrm{N} 2-\mathrm{Zr}-\mathrm{N} 2^{\text {ii }}$ & $74.4(2)$ \\
$\mathrm{N} 4-\mathrm{Zr}-\mathrm{N} 2^{\text {ii }}$ & $116.0(2)$ & $\mathrm{N} 4-\mathrm{Zr}-\mathrm{N} 6$ & $143.6(2)$ \\
$\mathrm{N} 4-\mathrm{Zr}-\mathrm{N} 8$ & $79.2(2)$ & $\mathrm{N} 4-\mathrm{Zr}-\mathrm{N} 10$ & $77.9(2)$ \\
$\mathrm{N} 6-\mathrm{Zr}-\mathrm{N} 10$ & $114.0(2)$ & $\mathrm{N} 8-\mathrm{Zr}-\mathrm{N} 10$ & $73.8(2)$ \\
$\mathrm{N} 2-\mathrm{Zr}-\mathrm{N} 10$ & $142.3(2)$ & $\mathrm{N} 6-\mathrm{Zr}-\mathrm{N} 8$ & $72.3(2)$ \\
$\mathrm{N} 4-\mathrm{Zr}-\mathrm{N} 8^{\text {ii }}$ & $142.2(2)$ & $\mathrm{N} 2-\mathrm{Zr}-\mathrm{N} 8^{\text {ii }}$ & $140.9(2)$ \\
$\mathrm{N} 4-\mathrm{Zr}-\mathrm{N} 4^{\text {ii }}$ & $70.8(2)$ & $\mathrm{N} 8-\mathrm{Zr}-\mathrm{N} 8^{\text {ii }}$ & $115.3(3)$ \\
\hline
\end{tabular}

Symmetry code: ${ }^{\mathrm{i}} 1-x, 1-y, 1-z ;{ }^{\text {ii }} x, 1 / 2-y, z$. eter equipped with a photomultiplier-type detector and phonon-counting hardware. $90^{\circ}$ geometry was used. An argon-ion laser line at $514.5 \mathrm{~nm}$ at $100 \mathrm{~mW}$ power was used as the exciting radiation. The resolution was set at $3 \mathrm{~cm}^{-1}$.

\section{4. $U V-V i s$ spectroscopy}

Measurements of the electronic spectra of $\left[\mathrm{ZrPc}_{2}\right] \mathrm{IBr}_{2}$ and $\mathrm{ZrPc}_{2}$ were carried out at room temperature using a Cary-Varian 2300 spectrometer. The UV-Vis spectra were recorded on a thin solid film between quartz glass prepared from a nujol mull, since a thin solid film of the $\left[\mathrm{ZrPc}_{2}\right] \mathrm{IBr}_{2}$ complex could not be obtained by sublimation in vacuum due to decomposition to $\mathrm{ZrPc}_{2}$ and $\mathrm{I}_{2}$ and $\mathrm{Br}_{2}$.

\subsection{Magnetic susceptibility measurement}

Magnetic susceptibility measurement of $\left[\mathrm{ZrPc}_{2}\right] \mathrm{IBr}_{2}$ was carried out on a solid sample of $100 \mathrm{mg}$ in the temperature range 300-2 K with a Quantum Design SQUID magnetometer (San Diego, CA). The susceptometer was calibrated with $\left(\mathrm{NH}_{4}\right)_{2} \mathrm{Mn}\left(\mathrm{SO}_{4}\right)_{2} \cdot 12 \mathrm{H}_{2} \mathrm{O}$. Data were recorded at a magnetic field of $0.5 \mathrm{~T}$.

\subsection{Electron paramagnetic resonance measurements}

EPR measurements were made on SE-Radiopan and ESR $300 \mathrm{E}$ - Bruker X-band spectrometers at room temperature and variable temperature $(300-90 \mathrm{~K})$ using cold $\mathrm{N}_{2}$ gas. The studies were carried out on solid samples of 4-10 mg. The concentrations of the free radicals in the samples of $\left[\mathrm{ZrPc}_{2}\right] \mathrm{IBr}_{2}$ were calculated using standard integration of the derivative signal and comparing the area with the area determined with the free radical standards. DPPH, TEMPO and TEMPOL were used as standards.

\subsection{Single-crystal electrical conductivity measurements}

Single crystals of $\left[\mathrm{ZrPc}_{2}\right] \mathrm{IBr}_{2}$ were mounted on silvered graphite fibers and electrical contacts were made with a palladium paste. Conductivity measurements were carried out along the $a$ and $c$ crystallographic axis (see Fig. 3a and b), i.e. along the stacks of one-electron oxidized $\left[\mathrm{ZrPc}_{2}\right]^{+}$units and perpendicular to the stacks using a standard four-point probe technique [45] with a sampling current of $20 \mu \mathrm{A}$. Variation of the temperature was archived by placing the samples in a cold-gas stream of $\mathrm{N}_{2}$ or He. The conductivity of the material was calculated from the relationship $\sigma=L / R A$, where $\sigma$ is the conductivity (in $\Omega^{-1} \mathrm{~cm}^{-1}$ ), $R$ is the measured resistance (in $\Omega$ ) of the material between two inner contacts (in $\mathrm{cm}$ ) and $A$ is the crosssectional area of the sample (in $\mathrm{cm}^{2}$ ). For the conductivity measurement a crystal was selected with the greatest dimension of $0.834 \mathrm{~mm}$ (along the $a$ axis), $0.456 \mathrm{~mm}$ (along the $c$ axis) and $0.246 \mathrm{~mm}$ (along the $b$ axis). The estimated uncertainty in these measurements is about $0.001 \mathrm{~mm}$. The area $A$ was estimated from the cross-sectional distance as 
observed with a microscope. An empirical analysis of the measurement errors indicates that the area is uncertain by $\delta A / A \approx \pm 0.1$, leading to an uncertainty $\Delta \sigma / \sigma \approx 0.2$. The measurements were repeated on four single crystals with different dimensions $(0.504-0.834,0.322-0.456$ and $0.186-0224 \mathrm{~mm}$ along the $a, c$ and $b$ axes, respectively). The differences in the measured conductivities on these single crystals are less than $5 \%$. The conductivity measured on a single crystal perpendicular to the stacks of $\left[\mathrm{ZrPc}_{2}\right]^{+}$units (i.e. along the $c$ axis) is smaller by a factor of $\sim 10^{3}$ than the conductivity along the stacks ( $a$ axis).

\section{Results and discussion}

\subsection{Synthesis}

Our preparation method leads directly to good-quality single crystals. The oxidation of the phthalocyaninato ring $\mathrm{Pc}(2-) \rightarrow \mathrm{Pc}(1-)$ by iodine is well known [46] and has been widely used to obtain partially oxidized metallophthalocyaninato and diphthalocyaninato complexes. $\mathrm{IBr}$ is a stronger oxidant than $\mathrm{I}_{2}$ [47]. The synthesis of $\left[\mathrm{ZrPc}_{2}\right] \mathrm{IBr}_{2}$ from phthalonitrile and pure powdered zirconium under a stream of $\mathrm{IBr}$ requires the formation of the heterotrihalide $\mathrm{IBr}_{2}{ }^{-}$ions, i.e. electron-rich three center bonding mixed trihalide ions [48]. The formation of the $\mathrm{IBr}_{2}{ }^{-}$ion by the reaction of $\mathrm{I}^{-}$with $\mathrm{Br}_{2}$ is well known [49]. However, under the used reaction conditions the $\mathrm{IBr}_{2}{ }^{-}$ion is the result of heterolitic thermal dissociation of $\mathrm{IBr}: 3 \mathrm{IBr} \leftrightarrow \mathrm{I}_{2} \mathrm{Br}^{+}+\mathrm{IBr}_{2}^{-}$ or by the series of reactions: $2 \mathrm{IBr}+2 \mathrm{e} \rightarrow \mathrm{I}_{2}+2 \mathrm{Br}^{-}$and $\mathrm{IBr}+\mathrm{Br}^{-} \rightarrow \mathrm{IBr}_{2}^{-}$. Thus the formation of the $\left[\mathrm{ZrPc}_{2}\right] \mathrm{IBr}_{2}$ complex can be write as shown in Scheme 1, where $\mathrm{Pc}=\mathrm{C}_{32} \mathrm{H}_{16} \mathrm{~N}_{8}$. During synthesis the $\left[\mathrm{ZrPc}_{2}\right] \mathrm{IBr}_{2}$, crystals grew in the hot part $\left(\sim 220^{\circ} \mathrm{C}\right)$ of the ampoule, and the $\mathrm{I}_{2}$ resublimed in the cooler part. The crystals of $\left[\mathrm{ZrPc}_{2}\right] \mathrm{IBr}_{2}$ are air and light stable. Iodine as an impurity is easily lost by cooling up to $\sim 45^{\circ} \mathrm{C}(10-15 \mathrm{~min})$ or by exposure to air at room temperature (3-4 days).

The obtained $\left[\mathrm{ZrPc}_{2}\right] \mathrm{IBr}_{2}$ crystals are insoluble in water, ethanol and methanol and are slightly soluble in pyridine, DMF, DMSO, chloronaphthalene and other high boiling aromatic solvents. However, after several days a black powder material from the solution was obtained. Elemental analysis of this powder material is consistent with a $\mathrm{ZrPc}_{2}$ complex that has been characterised earlier [41,50]. Thus it was found that a decomposition process takes place in solution. This process depends strongly on the temperature and is several times quicker in hot solvents. Contact of $\left[\mathrm{ZrPc}_{2}\right] \mathrm{IBr}_{2}$ with dilute inorganic acids $\left(\mathrm{H}_{2} \mathrm{SO}_{4}, \mathrm{HNO}_{3}\right.$ and their mixture or mixture with concentrated $\mathrm{HCl}$ ) leads to

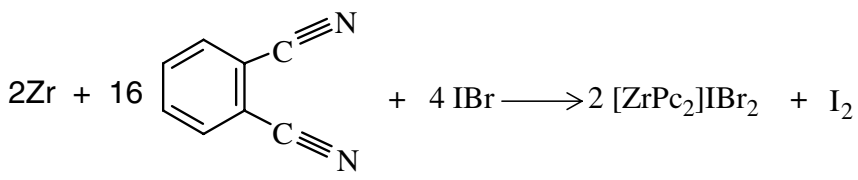

Scheme 1. Formation of the $\left[\mathrm{ZrPc}_{2}\right] \mathrm{IBr}_{2}$ complex; $\mathrm{Pc}=\mathrm{C}_{32} \mathrm{H}_{16} \mathrm{~N}_{8}$. demetallation, yielding the $\alpha$-form of metal-free phthalocyanine $\left(\alpha-\mathrm{H}_{2} \mathrm{Pc}\right)[51]$ and the appropriate salts.

\subsection{Raman spectroscopy}

In order to relate the charge transport properties the 'ionicity', i.e. the degree of oxidation of the $\left[\mathrm{ZrPc}_{2}\right]$ unit, must be determined. Resonance Raman spectroscopy is useful for identification of the anionic part of the complex. The resonance Raman spectrum measured on a polycrystalline sample at room temperature (Fig. 1) exhibits only one strong fundamental band at $169 \mathrm{~cm}^{-1}$ (the expected value for $\mathrm{IBr}_{2}{ }^{-}$is $168 \mathrm{~cm}^{-1}$ [52]). The absence of a band at $\sim 110 \mathrm{~cm}^{-1}$ eliminates $\mathrm{I}_{3}{ }^{-}$ions and the absence of a peak at $\sim 160 \mathrm{~cm}^{-1}$ eliminates $\mathrm{Br}_{3}{ }^{-}$ions $[19,20]$. Free $\mathrm{Br}_{2}$ $\left(v \approx 306 \mathrm{~cm}^{-1}\right)[53,54]$ and free $\mathrm{I}_{2}\left(v \approx 210 \mathrm{~cm}^{-1}\right)[55]$ are not present in detectable quantities in the crystals.

\subsection{Description of the structure}

The crystals of $\left[\mathrm{ZrPc}_{2}\right] \mathrm{IBr}_{2}$ are built up from one-electron oxidized $\left[\mathrm{ZrPc}_{2}\right]^{+}$sandwich units and mixed trihalide $\mathrm{IBr}_{2}{ }^{-}$counter ions. The $\left[\mathrm{ZrPc}_{2}\right]^{+}$unit is located on a special position and has crystallographic $m$ symmetry, while the I atom of the $\mathrm{IBr}_{2}{ }^{-}$ion occupies the inversion center, so the $\mathrm{IBr}_{2}{ }^{-}$ion is linear and symmetrical. The central closed shell $\mathrm{Zr}^{4+}$ cation $\left(\mathrm{d}^{0}\right.$ configuration) is eight coordinated by two saucer shaped phthalocyaninato units (Fig. 2): $\mathrm{Pc}^{2-}$ and one-electron oxidized $\mathrm{Pc}^{-} \pi$-radical ligands (identified by EPR spectroscopy). This may be the reason for the slightly asymmetric location of the $\mathrm{Zr}^{4+}$ cation between the phthalocyaninato rings. The average $\mathrm{Zr}-\mathrm{N}$ distance to one $\mathrm{Pc}$ ring is equal to $2.283 \AA$ and is slightly longer $(2.344 \AA)$ than to the other Pc ring. On the other hand the slightly asymmetric location of the $\mathrm{Zr}^{4+}$ cation between the phthalocyaninato rings (1.233(3) $\AA$ from the $\mathrm{N}_{4}$ plane of one Pc ring and 1.244(3) $\AA$ from the $\mathrm{N}_{4}$ plane of the second ring) is due to the different interaction of the phthalocyaninato rings with the $\mathrm{IBr}_{2}{ }^{-}$ion that is located closely to the one of them. In conclusion, most probably the $\mathrm{Zr}^{4+}$ cation is sandwiched between the two phthalocyaninato macrocyclic rings with a non-integral formal oxidation state of -1.5 .

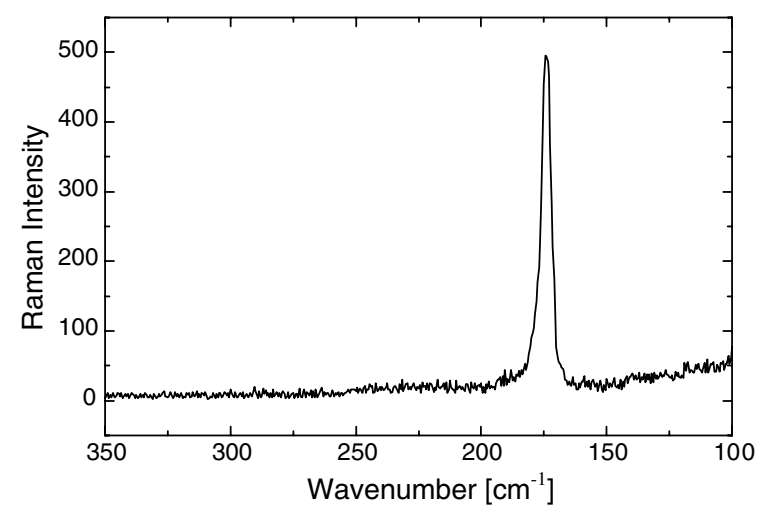

Fig. 1. Resonance Raman spectrum of $\left[\mathrm{ZrPc}_{2}\right] \mathrm{IBr}_{2}$ at room temperature. 


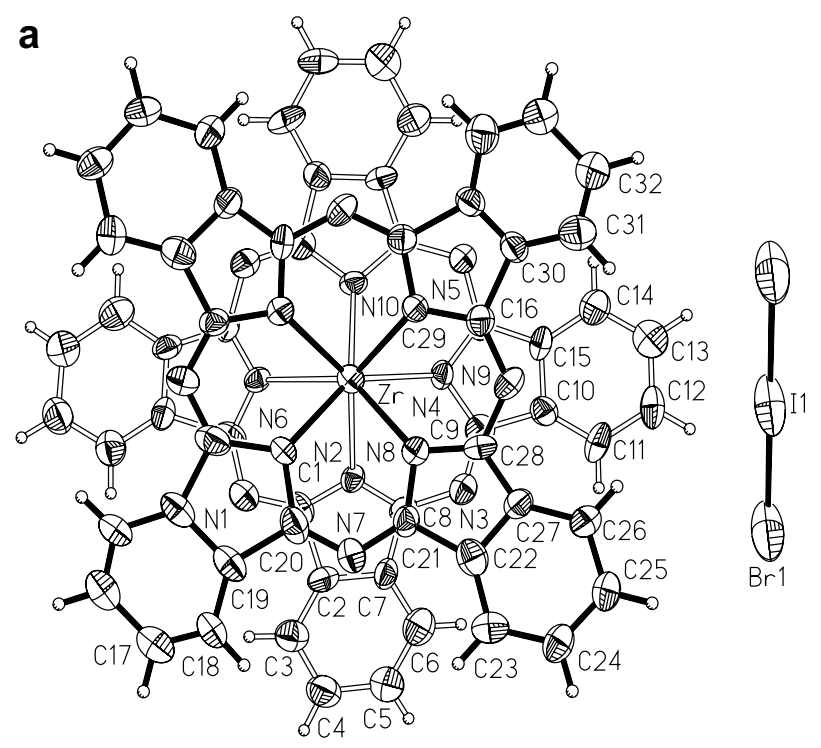

b

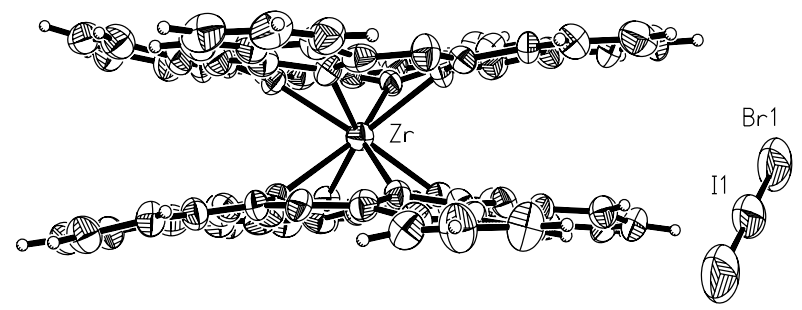

Fig. 2. Molecular structure of $\left[\mathrm{ZrPc}_{2}\right] \mathrm{IBr}_{2}$, top view (a) and side view (b). Displacement ellipsoids are shown at the $50 \%$ probability level.

Similarly a non-integral oxidation state of the Pc ring is observed in the class of partially oxidized $\operatorname{MPc}\left(\mathrm{I}_{3}\right)_{2 / 3}$, $\left[\mathrm{MPc}_{2}\right]\left(\mathrm{I}_{3}\right)_{2 / 3}$ or $\left[\mathrm{MPc}_{2}\right]\left(\mathrm{I}_{3}\right)_{5 / 9}$ complexes, in which the formal oxidation state of Pc ring equals -1.667 or -1.772 $[35,37]$. Both phthalocyaninato macrocyclic rings of the $\left[\mathrm{ZrPc}_{2}\right]^{+}$unit are significantly deviated from the weighted least-squares plane defined by four $\mathrm{N}$-isoindole atoms. The largest deviations from the $\mathrm{N}_{4}$-isoindole planes are observed for C5 (1.109 $⿱$ ) for one Pc ring and C24 $(0.762 \AA)$ for the second Pc ring. The distortion of the phthalocyaninato rings from planarity is comparable to that found in the crystal of $\left[\mathrm{ZrPc}_{2}\right]\left(\mathrm{I}_{3} \cdot \mathrm{I}_{2}\right)$ [39], but is smaller than that in the crystal of unoxidized $\mathrm{ZrPc}_{2}$, in which the greatest deviation equals $1.47 \AA$ [41]. The distortion of the phthalocyaninato macrocyclic rings of the zirconium diphthalocyaninato complexes, that can be estimated by the bending of the isoindole units with respect to the $\mathrm{N}_{4}$ core and by the "twisting" of the peripheral carbon atoms of benzene rings, is collected in Table 3. The displacements of the carbon atoms of the benzene rings for some metallodiphthalocyaninato structures [55-61] are listed in Table 4, for a comparison. As can be seen from Tables 3 and 4, both one-electron oxidized zirconium diphthalocyanines, [ $\left.\mathrm{ZrPc}_{2}\right]-$ $\mathrm{IBr}_{2}$ and $\left[\mathrm{ZrPc}_{2}\right] \mathrm{I}_{3} \cdot \mathrm{I}_{2}$, and unoxidized $\mathrm{ZrPc}_{2}$ contain the most deviated phthalocyaninato rings. The $\mathrm{Zr}-\mathrm{N}$ distances in $\left[\mathrm{ZrPc}_{2}\right] \mathrm{IBr}_{2}$ range from 2.280(5) to 2.377(4) $\AA$, and are compared with the distances in the $\left[\mathrm{ZrPc}_{2}\right] \mathrm{I}_{3} \cdot \mathrm{I}_{2}$ complex [39], but they are slightly shorter than those observed in the crystal structure of the unoxidized $\mathrm{ZrPc}_{2}$ complex [41]. This is likely due to the weaker repulsive interaction between $\mathrm{Pc}^{2-}$ and the one-electron oxidized $\mathrm{Pc}^{-\cdot} \pi$-radical ligand in relation to the unoxidized $\mathrm{ZrPc}_{2}$, in which the $\mathrm{Pc}$...Pc interaction is undoubtedly greater, since both $\mathrm{Pc}$ rings are $2-$. The $\mathrm{M}-\mathrm{N}$ distances in zirconium diphthalocyaninato complexes are shorter than those of the other sandwich-type metallodiphthalocyaninato structures due to the relatively small radius of the $\mathrm{Zr}^{4+}$ cation [62]. The effect of the small radius of $\mathrm{Zr}^{4+}$ and its great formal oxidation state are the reasons for the more closely located phthalocyaninato macrocyclic rings around the $\mathrm{Zr}^{4+}$ cation, and the distance between the $\mathrm{N}_{4}$-isoindole planes is the shortest within the sandwich-type metallodiphthalocyanines (see Table 5). The Pc rings in $\left[\mathrm{ZrPc}_{2}\right] \mathrm{IBr}_{2}$, similarly to $\left[\mathrm{ZrPc}_{2}\right] \mathrm{I}_{3} \cdot \mathrm{I}_{2}$, are staggered at an angle of $45.0(3)^{\circ}$ and this is an additional reason for the closer location of the $\mathrm{Pc}$ rings in relation to the unoxidized $\mathrm{ZrPc}_{2}$ complex in which the rotation angle of the $\mathrm{Pc}$ rings is equal to $42^{\circ}$ [41]. The close proximity of the $\mathrm{N}_{4}$-planes of the Pc rings indicates the strong interaction of the $\pi$-clouds and adds to the distortion of the rest of Pc rings from the $\mathrm{N}_{4}$-planes. The $\pi-\pi$ interaction is a common feature in the field of phthalocyanine chemistry, and it leads phthalocyanine and its metal complexes to form supramolecular aggregates [63-66]. The staggered orientation of the $\mathrm{Pc}$ rings give the square antiprismatic coordination of the central $\mathrm{Zr}^{4+}$ cation and, as can be seen from the Fig. 2a, indicates that the outermost carbon atoms of the benzene rings are apart, as for non-interpenetrating $\pi$-clouds. In the third crystal of

\section{Table 3}

Distortion of the phthalocyaninato rings in partially oxidized zirconium diphthalocyaninato complexes

\begin{tabular}{|c|c|c|c|c|c|c|c|c|c|c|c|c|c|c|}
\hline \multirow[t]{2}{*}{ Compound } & \multicolumn{5}{|c|}{$\begin{array}{l}\text { Bending of the isoindole }{ }^{\mathrm{a}} \text { with respect to } \\
\text { the } \mathrm{N}_{4} \text { plane }\left(^{\circ}\right) \text {, e.s.d.'s }=0.02\end{array}$} & \multicolumn{8}{|c|}{$\begin{array}{l}\text { "Twisting" of the external phenyl ring given by the displacement of the } \\
\text { outermost carbon atoms of the phenyl ring }(\AA) \text {, e.s.d.'s }=0.01\end{array}$} & \multirow[t]{2}{*}{ Ref. } \\
\hline & $\mathrm{N} 2$ & N4 & N6 & N8 & N10 & $\mathrm{C} 4$ & $\mathrm{C} 5$ & $\mathrm{C} 12$ & $\mathrm{C} 13$ & $\mathrm{C} 24$ & $\mathrm{C} 25$ & $\mathrm{C} 17$ & $\mathrm{C} 32$ & \\
\hline \multirow{5}{*}{$\begin{array}{l}{\left[\mathrm{ZrPc}_{2}\right] \mathrm{IBr}_{2}} \\
{\left[\mathrm{ZrPc}_{2}\right] \mathrm{I}_{3} \cdot \mathrm{I}_{2}} \\
{\left[\mathrm{ZrPc}_{2}\right]\left(\mathrm{I}_{3}\right)_{2 / 3}} \\
\mathrm{ZrPc}_{2}{ }^{\mathrm{b}}\end{array}$} & 12.7 & 4.3 & 4.5 & 9.5 & 9.1 & 0.93 & 1.11 & 0.40 & 0.37 & 0.76 & 0.70 & 0.44 & 0.70 & \multirow{2}{*}{$\begin{array}{l}\text { this work } \\
{[39]}\end{array}$} \\
\hline & 15.8 & 4.7 & 14.3 & 7.6 & 7.5 & 0.39 & 0.46 & 1.31 & 1.10 & 0.54 & 0.65 & 1.07 & 0.68 & \\
\hline & \multicolumn{13}{|c|}{ Both Pc-rings are closely planar, due to crystal symmetry of $P 4 / m c c$} & {$[38]$} \\
\hline & 18.6 & 11.8 & 6.6 & 11.4 & & 1.49 & 1.35 & 0.77 & 0.93 & 0.54 & 0.44 & 0.87 & 0.93 & \multirow[t]{2}{*}[41]{} \\
\hline & 14.9 & 12.3 & 14.8 & 8.0 & & 1.22 & 1.21 & 0.99 & 0.99 & & 1.22 & 0.70 & 0.66 & \\
\hline
\end{tabular}

\footnotetext{
${ }^{\mathrm{a}}$ Isoindole rings: N2, C1-C8; N4, C9-C16; N6, C17-C20, C17 ${ }^{\mathrm{ii}}-\mathrm{C} 20^{\mathrm{ii}}$; and N8, C21-C28; N10, C29-C32, C29 ${ }^{\mathrm{ii}}-\mathrm{C} 32^{\mathrm{ii}}$ (see Fig. 2 for labelling).

${ }^{\mathrm{b}}$ First line related the one Pc ring, the second line related the other Pc ring in $\mathrm{ZrPc}_{2}$.
} 
Table 4

Comparison of the displacements of the outermost carbon atoms of phenyl rings from the $\mathrm{N}_{4}$-isoindole plane in some metallodiphthalocyaninato $\left(\mathrm{MPc}_{2}\right)$ structures

\begin{tabular}{|c|c|c|c|}
\hline \multirow[t]{2}{*}{ Compound } & \multicolumn{2}{|c|}{$\begin{array}{l}\text { Displacement of the phenyl ring } \mathrm{C} \\
\text { atoms from the } \mathrm{N}_{4} \text {-isoindole plane }\end{array}$} & \multirow[t]{2}{*}{ Ref. } \\
\hline & $\begin{array}{l}\text { Least displaced } \\
(\AA)\end{array}$ & $\begin{array}{l}\text { Most displaced } \\
(\AA)\end{array}$ & \\
\hline$\left[\mathrm{ZrPc}_{2}\right] \mathrm{IBr}_{2}$ & $0.37(1)$ & $1.11(1)$ & this work \\
\hline$\left[\mathrm{ZrPc}_{2}\right] \mathrm{I}_{3} \cdot \mathrm{I}_{2}$ & 0.37 & 1.31 & {$[39]$} \\
\hline $\mathrm{ZrPc}_{2}$ & 0.49 & 1.47 & {$[41]$} \\
\hline$\left[\mathrm{ZrPc}_{2}\right]\left(\mathrm{I}_{3}\right)_{2 / 3}{ }^{\mathrm{a}}$ & 0 & 0 & {$[38]$} \\
\hline$\alpha-\mathrm{SnPc}_{2}$ & 0.18 & 1.01 & {$[56]$} \\
\hline$\beta-\mathrm{SnPc}_{2}$ & 0.25 & 1.21 & {$[57]$} \\
\hline $\mathrm{Ln}^{(\mathrm{III})} \mathrm{Pc}_{2}$ & 0.25 & 1.10 & {$[58]$} \\
\hline $\mathrm{TiPc}_{2}{ }^{\mathrm{b}}$ & 1.06 & 1.94 & [59] \\
\hline$\left[\mathrm{Nb}^{(\mathrm{V})} \mathrm{Pc}_{2}\right] \mathrm{IBr}_{2}^{\mathrm{b}}$ & 0.91 & 1.53 & {$[60]$} \\
\hline$\left[\mathrm{Nb}^{(\mathrm{V})} \mathrm{Pc}_{2}\right] \mathrm{IBr}_{2} \cdot \mathrm{I}_{2}^{\mathrm{b}}$ & 0.73 & 1.85 & {$[60]$} \\
\hline$\left[\mathrm{TiPc}_{2}\right]\left(\mathrm{I}_{3}\right)_{2 / 3}$ & 0.61 & 0.67 & {$[33]$} \\
\hline $\mathrm{UPc}_{2}$ & 0.48 & 1.10 & {$[61]$} \\
\hline$\left[\mathrm{UPc}_{2}\right]\left(\mathrm{I}_{3}\right)_{5 / 9}{ }^{\mathrm{a}}$ & 0 & 0 & {$[35]$} \\
\hline$\left[\mathrm{UPc}_{2}\right]\left(\mathrm{I}_{3}\right)_{2 / 3}$ & 0.083 & 0.335 & {$[37]$} \\
\hline $\mathrm{In}^{(\mathrm{III})} \mathrm{Pc}_{2}$ & 0.12 & 0.88 & [32] \\
\hline$\left[\operatorname{In}^{(\mathrm{III})} \mathrm{Pc}_{2}\right]\left(\mathrm{I}_{3}\right)_{2 / 3}{ }^{\mathrm{a}}$ & 0 & 0 & {$[38]$} \\
\hline
\end{tabular}

partially oxidized zirconium diphthalocyanine, $\left[\mathrm{ZrPc}_{2}\right]\left(\mathrm{I}_{3}\right)_{2 / 3}$, the relatively long $\mathrm{N}_{4}-\mathrm{N}_{4}$ interplanar distance is due to the symmetry of the crystal (tetragonal system), and the space group of $P 4 / m c c$ requires the location of the Pc rings on the special position in the crystal (the Pc rings are located on the crystallographic $m$ plane) [38]. As can be seen from Tables 4 and 5 , the greatest distortion of the Pc rings from planarity and the shortest $\mathrm{N}_{4}-\mathrm{N}_{4}$ interplanar distances are observed for $\left[\mathrm{NbPc}_{2}\right] \mathrm{IBr}_{2} \cdot \mathrm{I}_{2}$ and $\left[\mathrm{NbPc}_{2}\right] \mathrm{IBr}_{2}$ [60], as well as for $\mathrm{TiPc}_{2}$ [59]. However, these three complexes belong to the new family of sandwiched metallodiphthalocyaninato complexes in which the close proximity of the $\mathrm{Pc}$ rings is due to two interligand $\mathrm{C}-\mathrm{C}$ $\sigma$-bonds that have stapled both phthalocyaninato rings $[59,60]$. In this family of sandwiched $\mathrm{MPc}_{2}$ complexes the delocalisation of the $\pi$-electrons in the inner 16-membered rings breaks down due to two $\mathrm{C}$ atoms with $\mathrm{sp}^{3}$ hybridisation and the formation of the interligand $\sigma$-bonds. Additionally, it should be added that oxidation of the stapled $\mathrm{TiPc}_{2}$ complex by iodine leads to the breaking of the interligand $\mathrm{C}-\mathrm{C} \sigma$-bonds [33].

The one-electron oxidized $\left[\mathrm{ZrPc}_{2}\right]^{+}$units of $\left[\mathrm{ZrPc}_{2}\right] \mathrm{IBr}_{2}$ in the crystal, similarly as in $\left[\mathrm{ZrPc}_{2}\right] \mathrm{I}_{3} \cdot \mathrm{I}_{2}$, form pseudomono-dimensional columnar stacks that are aligned along the $a$ axis of the crystal (see Fig. 3a), and the mean planes of the phthalocyaninato rings are parallel to the $b c$ plane (Fig. 3b). However, the anionic parts of these complexes are different $\left(\mathrm{IBr}_{2}{ }^{-}\right.$in one and $\mathrm{I}_{3}{ }^{-} \cdot \mathrm{I}_{2}$ in the second) and also are located differently in relation to the stacking columns of the $\left[\mathrm{ZrPc}_{2}\right]^{+}$units. In the crystal of $\left[\mathrm{ZrPc}_{2}\right] \mathrm{I}_{3} \cdot \mathrm{I}_{2}$ the slight bending of $\mathrm{I}_{3}{ }^{-}$ions due to the interaction with neutral $\mathrm{I}_{2}$ molecules are parallel to the $b$ crystallographic axis and together with $I_{2}$ neutral molecules form zigzag chains that are perpendicular to the columnar stacks of the $\left[\mathrm{ZrPc}_{2}\right]^{+}$units [39]. In this $\left[\mathrm{ZrPc}_{2}\right] \mathrm{IBr}_{2}$ crystal structure, the symmetrical mixed trihalide $\mathrm{IBr}_{2}{ }^{-}$that is located in the inversion center forms angles of $104.7(3)^{\circ}, 47.3(3)^{\circ}$ and $129.4(3)^{\circ}$ with the $a, b$ and $c$ axes of the crystal, respectively. This structure $\left(\left[\mathrm{ZrPc}_{2}\right] \mathrm{IBr}_{2}\right)$ is also different from the third zirconium diphthalocyaninato complex $\left[\mathrm{ZrPc}_{2}\right]\left(\mathrm{I}_{3}\right)_{2 / 3}$ [38] in several aspects. The Pc rings of $\left[\mathrm{ZrPc}_{2}\right]\left(\mathrm{I}_{3}\right)_{2 / 3}$ are crystallographically constrained to lie in the $(001)$ plane of its tetragonal unit cell, so they are planar and strictly perpendicular to the stacking axis that is also the unique axis. Two Pc rings of $\left[\mathrm{ZrPc}_{2}\right]\left(\mathrm{I}_{3}\right)_{2 / 3}$ are rotated by $42^{\circ}$, and are separated by a distance of $3.244(3) \AA$, which is significantly longer than the $\mathrm{N}_{4}-\mathrm{N}_{4}$ interplanar distance in the $\left[\mathrm{ZrPc}_{2}\right] \mathrm{IBr}_{2}$ crystal. The anionic part of the $\left[\mathrm{ZrPc}_{2}\right]\left(\mathrm{I}_{3}\right)_{2 / 3}$ complex, i.e. the iodine doped atoms, form linear and symmetrical triiodide ions that in the crystal are disordered and located in the channels between the columnar stacks of $\left[\mathrm{ZrPc}_{2}\right]^{2 / 3+}$ units, thus both mono-dimensional aggregates are parallel [38]. In the crystal of $\left[\mathrm{ZrPc}_{2}\right] \mathrm{IBr}_{2}$, the monodimensional columns of $\left[\mathrm{ZrPc}_{2}\right]^{+}$units are not parallel to the linear $\mathrm{IBr}_{2}{ }^{-}$ions. Additionally, due to the crystal symmetry and the space group of $P 4 / m c c$, the central

Table 5

Comparison of the coordination of the central metal ion of some $\mathrm{MPc}_{2}$ structures

\begin{tabular}{|c|c|c|c|c|c|}
\hline Compound & $\begin{array}{l}\text { Formal oxidation } \\
\text { state of Pc ring }\end{array}$ & $\begin{array}{l}\text { Average } \mathrm{M}-\mathrm{N} \text { bond } \\
\text { distance }(\AA)\end{array}$ & $\begin{array}{l}\text { Distance between } \\
\mathrm{N}_{4}-\mathrm{N}_{4} \text { plane }(\AA)\end{array}$ & $\begin{array}{l}\text { Staggering } \\
\text { angle }\left({ }^{\circ}\right)\end{array}$ & Ref. \\
\hline$\left[\mathrm{ZrPc}_{2}\right] \mathrm{IBr}_{2}$ & -1.5 & 2.314 & $2.434(3)$ & $45.0(3)$ & this work \\
\hline$\left[\mathrm{ZrPc}_{2}\right] \mathrm{I}_{3} \cdot \mathrm{I}_{2}$ & -1.5 & 2.297 & $2.494(3)$ & $45.0(2)$ & {$[39]$} \\
\hline$\left[\mathrm{ZrPc}_{2}\right]\left(\mathrm{I}_{3}\right)_{2 / 3}$ & -1.667 & 2.527 & $3.244(3)$ & $40.6(2)$ & {$[38]$} \\
\hline $\mathrm{ZrPc}_{2}$ & -2 & 2.30 & 2.52 & 42 & {$[41]$} \\
\hline $\mathrm{UPc}_{2}$ & -2 & 2.43 & 2.81 & 37 & {$[61]$} \\
\hline$\left[\mathrm{UPc}_{2}\right]\left(\mathrm{I}_{3}\right)_{5 / 9}$ & -1.667 & 2.448 & $2.903(5)$ & $40.2(6)$ & {$[37]$} \\
\hline$\left[\mathrm{UPc}_{2}\right]\left(\mathrm{I}_{3}\right)_{2 / 3}$ & -1.772 & 2.549 & $3.250(1)$ & $40.7(6)$ & {$[35]$} \\
\hline $\mathrm{In}^{(\mathrm{III})} \mathrm{Pc}_{2}$ & -1.5 & 2.333 & $2.741(9)$ & $42.2(4)$ & {$[32]$} \\
\hline$\left[\operatorname{In}^{(\mathrm{III})} \mathrm{Pc}_{2}\right]\left(\mathrm{I}_{3}\right)_{2 / 3}$ & -1.167 & 2.523 & $3.196(1)$ & $40.0(4)$ & {$[38]$} \\
\hline$\left[\mathrm{Nb}^{(\mathrm{V})} \mathrm{Pc}_{2}\right] \mathrm{IBr}_{2}^{\mathrm{a}}$ & -2 & 2.21 & $2.331(5)$ & 45.0 & {$[60]$} \\
\hline$\left[\mathrm{Nb}^{(\mathrm{V})} \mathrm{Pc}_{2}\right] \mathrm{IBr}_{2} \cdot \mathrm{I}_{2}{ }^{\mathrm{a}}$ & -2 & 2.21 & $2.148(6)$ & 45.0 & {$[60]$} \\
\hline $\mathrm{TiPc}_{2}{ }^{\mathrm{a}}$ & -2 & 2.22 & 2.32 & 45 & {$[59]$} \\
\hline$\left[\mathrm{TiPc}_{2}\right]\left(\mathrm{I}_{3}\right)_{2 / 3}$ & -1.667 & 2.246 & 2.42 & 41.1 & {$[33]$} \\
\hline
\end{tabular}

a 'Stapled' by two $\mathrm{C}-\mathrm{C} \sigma$ bonds. 

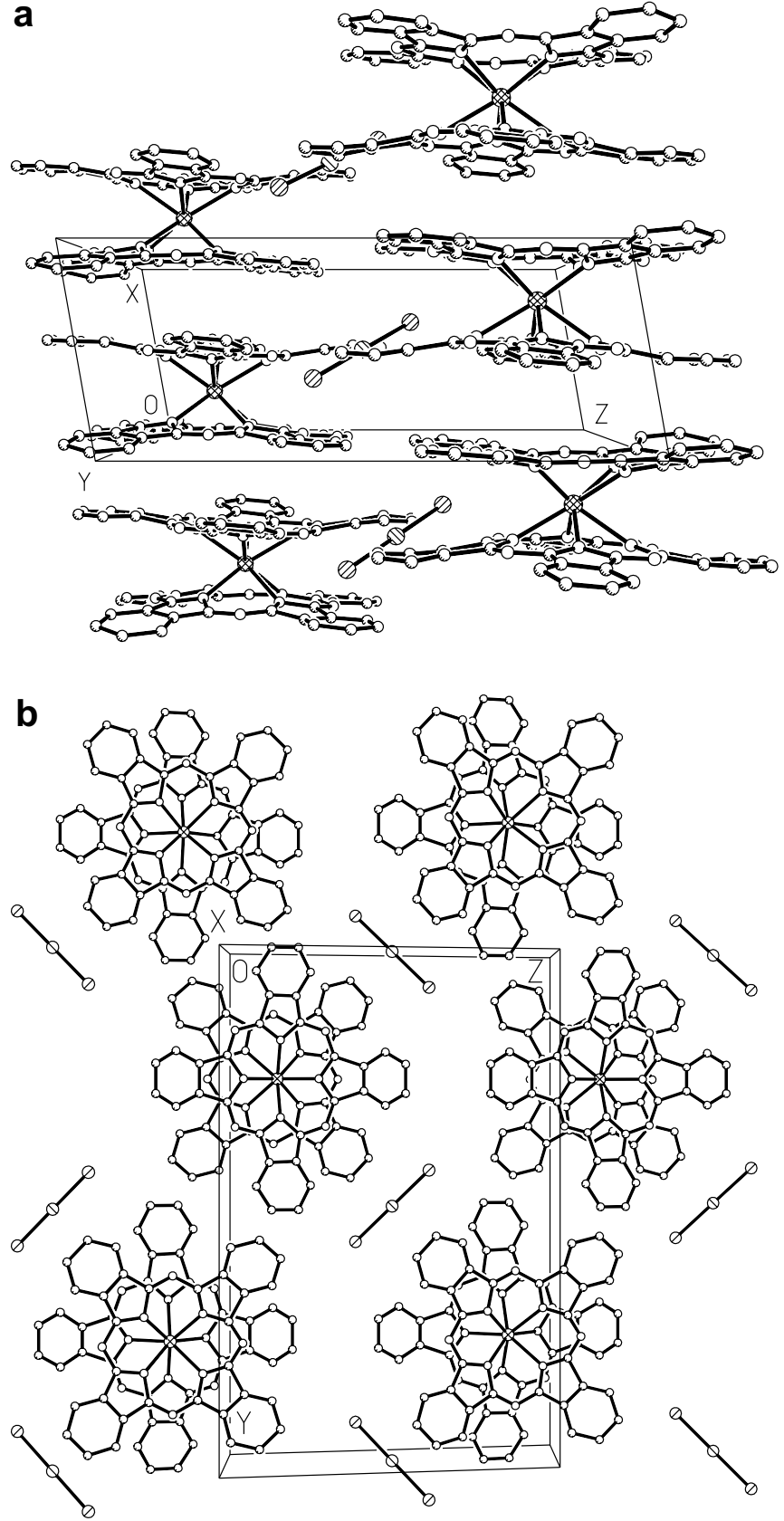

Fig. 3. View of the crystal structure of $\left[\mathrm{ZrPc}_{2}\right] \mathrm{IBr}_{2}$ perpendicular to the stacks of $\left[\mathrm{ZrPc}_{2}\right]^{+}$units (a) and along the stacks (b).

$\mathrm{Zr}^{4+}$ cation in the crystal of $\left[\mathrm{ZrPc}_{2}\right]\left(\mathrm{I}_{3}\right)_{2 / 3}$ is statistically distributed over two symmetrically equivalent positions, in the $\left[\mathrm{ZrPc}_{2}\right] \mathrm{IBr}_{2}$ crystal the $\mathrm{Zr}^{4+}$ cation is ordered. One more difference between the $\left[\mathrm{ZrPc}_{2}\right] \mathrm{IBr}_{2}$ and $\left[\mathrm{ZrPc}_{2}\right]\left(\mathrm{I}_{3}\right)_{2 / 3}$ complexes should be noted, the difference in the formal oxidation state of the cationic sandwich $\left[\mathrm{ZrPc}_{2}\right]$ unit, +1 and $+2 / 3$ in $\left[\mathrm{ZrPc}_{2}\right] \mathrm{IBr}_{2}$ and $\left[\mathrm{ZrPc}_{2}\right]\left(\mathrm{I}_{3}\right)_{2 / 3}$, respectively. The formal oxidation state of the $\left[\mathrm{ZrPc}_{2}\right]$ units correlate with the holes of the electrons on the Pc rings that are strictly connected with the charge transport properties. The intermolecular back-to-back Pc ...P Pc distances in the crystal of $\left[\mathrm{ZrPc}_{2}\right] \mathrm{IBr}_{2}$, with an average value of $\sim 3.35 \AA$ between two neighbouring $\left[\mathrm{ZrPc}_{2}\right]^{+}$units, indicates a $\pi-\pi$ interaction between the Pc rings within the columns, since this value is slightly shorter than the van der Waals distance of $3.4 \AA$ for aromatic carbon atoms [67]. This $\pi-\pi$ intermolecular interaction plays an important role in the charge transport.

The $\mathrm{I}-\mathrm{Br}$ distances in the symmetrical $\mathrm{IBr}_{2}{ }^{-}[(\mathrm{Br}-\mathrm{I}-$ $\mathrm{Br})^{-}$] ion are equal to 2.694(1) $\mathrm{A}$. This value is compared to those found in the other metallophthalocyaninato complexes containing the $\mathrm{IBr}_{2}{ }^{-}$ion $[60,68]$. The $\mathrm{I}-\mathrm{Br}$ distances in the $\mathrm{I}_{2} \mathrm{Br}^{-}$ion $\left[(\mathrm{I}-\mathrm{Br}-\mathrm{I})^{-}\right]$are significantly longer as molecular orbital calculations show (the $\mathrm{I}-\mathrm{Br}$ distance in the $(\mathrm{I}-\mathrm{Br}-\mathrm{I})^{-}$ion is equal to $\sim 2.91 \AA$ ) [48] and compared with those obtained by X-ray experimental results $[69,70]$.

\section{4. $U V-V i s$ spectroscopy}

The solid-state electronic absorption spectra recorded at room temperature on a thin-film made from nujol mulls between quartz plates of one-electron oxidized $\left[\mathrm{ZrPc}_{2}\right] \mathrm{IBr}_{2}$ and unoxidized $\mathrm{ZrPc}_{2}$ are very similar (see Fig. 4). This indicates that the interaction between the $\left[\mathrm{ZrPc}_{2}\right]^{+}$and $\mathrm{IBr}_{2}{ }^{-}$units is insignificant in the positions of the phthalocyanine's HOMO and LUMO levels. The $\mathrm{Q}$ band arises from the excitation from HOMO $\left(\mathrm{a}_{1 \mathrm{u}}\right)$ to LUMO $\left(\mathrm{e}_{\mathrm{g}}\right)$, while the B-Soret band is mostly an $\mathrm{a}_{2 \mathrm{u}} \rightarrow \mathrm{e}_{\mathrm{g}}$ transition and the $\mathrm{N}$ band (at $\sim 297 \mathrm{~nm}$ in both complexes) resulting mainly from a transition $\mathrm{b}_{2 \mathrm{u}}(\pi) \rightarrow \mathrm{e}_{\mathrm{g}}\left(\pi^{*}\right)$. The $\mathrm{Q}$ band in the spectra of both complexes splits into two $\left(\mathrm{Q}_{1}\right.$ and $\left.\mathrm{Q}_{2}\right)$ bands: 696 and $635 \mathrm{~nm}$ in unoxidized $\mathrm{ZrPc}_{2}$ and 694 and $628 \mathrm{~nm}$ in one-electron oxidized $\left[\mathrm{ZrPc}_{2}\right] \mathrm{IBr}_{2}$. The splitting values of $61 \mathrm{~nm}$ in $\mathrm{ZrPc}_{2}$ and $66 \mathrm{~nm}$ in $\left[\mathrm{ZrPc}_{2}\right] \mathrm{IBr}_{2}$ result from the vibronic coupling in the excited state [71-73]. Several authors reported that the splitting value of the $\mathrm{Q}$ band depends on the interplanar Pc-Pc distance, and decreases as the interplanar Pc-Pc distance increases [74,75]. Additionally, Takahashi et al. [74,76]. reported that if the interplanar Pc-Pc distance increases the intensity of the $\mathrm{Q}_{1}$ band increases and the $\mathrm{Q}_{2}$ band decreases. The inversion

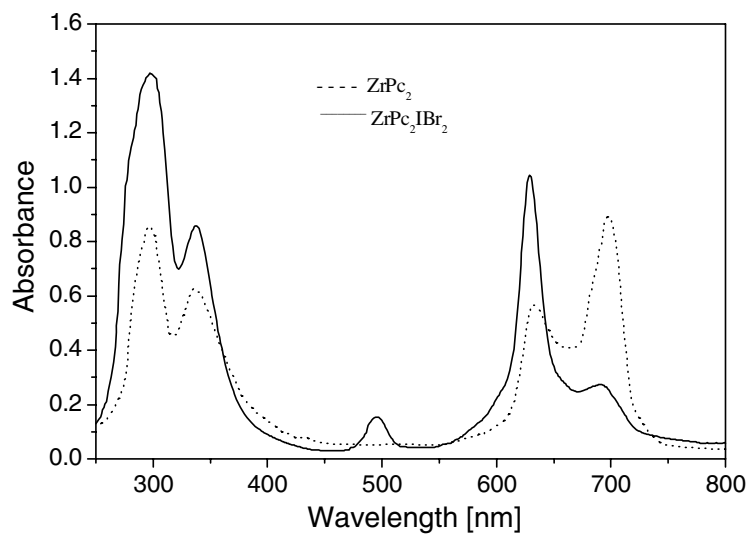

Fig. 4. Electronic absorption spectra of the one-electron oxidized $\left[\mathrm{ZrPc}_{2}\right] \mathrm{IBr}_{2}$ (solid line) and the non-oxidized $\mathrm{ZrPc}_{2}$ complexes (dashed line). 
of the intensities of the $\mathrm{Q}_{1}$ and $\mathrm{Q}_{2}$ bands and the splitting values in the spectra of $\mathrm{ZrPc}_{2}$ and $\left[\mathrm{ZrPc}_{2}\right] \mathrm{IBr}_{2}$ are fully consistent with the X-ray single crystal analysis (the interplanar Pc-Pc distance of 2.434(3) $\AA$ in one-electron oxidized $\left[\mathrm{ZrPc}_{2}\right] \mathrm{IBr}_{2}$ is shorter than in $\mathrm{ZrPc}_{2}(2.52 \AA)$ [41]).

In the spectrum of $\left[\mathrm{ZrPc}_{2}\right] \mathrm{IBr}_{2}$, besides the characteristic bands (N, B and Q) also observed in the spectrum of unoxidized $\mathrm{ZrPc}_{2}$, one additional band at $\sim 496 \mathrm{~nm}$ is observed. Several authors that studied iodine-doped metallophthalocyaninato complexes containing the triiodide $\mathrm{I}_{3}{ }^{-}$ions suggested that the optical transition at $\sim 500 \mathrm{~nm}$ may arise from a transition in the $\mathrm{I}_{3}{ }^{-}$ions, probably $\sigma_{\mathrm{g}} \rightarrow \sigma_{\mathrm{u}}^{*}$ split by spin-orbit coupling [54]. Gabes and Stufkens [77] studied the electronic absorption spectra of symmetrical and asymmetrical trihalide ions $\left(\mathrm{I}_{3}^{-}, \mathrm{IBr}_{2}{ }^{-}, \mathrm{ICI}_{2}{ }^{-}, \mathrm{Br}_{3}{ }^{-}\right.$and $\left.\mathrm{BrCl}_{2}{ }^{-}\right)$ observed in the spectrum of $\mathrm{IBr}_{2}{ }^{-}\left(\mathrm{CsIBr}_{2}\right)$ three bands at 248, 313 and $407 \mathrm{~nm}$ with decreasing intensities and one shoulder at about $493 \mathrm{~nm}$. The intensity of the band at $493 \mathrm{~nm}$ in relation to the bands at 248,313 and $407 \mathrm{~nm}$ is much lower [77] as well as lower than the intensities of the bands assigned to the transitions in the phthalocyaninato complexes. Therefore, the band observed at $496 \mathrm{~nm}$ in the spectrum of $\left[\mathrm{ZrPc}_{2}\right] \mathrm{IBr}_{2}$ complex is assigned to the electronic transition from a deeper level to the half-occupied HOMO level and is an evidence for the existence of the one-electron oxidized phthalocyaninato(1-) $\pi$-radical ligand . This assignment is supported by the fact that a similar band at $\sim 500 \mathrm{~nm}$ has been observed in the spectra of other one-electron oxidized metallodiphthalocyaninato complexes such as $\mathrm{Ln}^{(\mathrm{III})} \mathrm{Pc}_{2}$ and $\mathrm{In}^{(\mathrm{III})} \mathrm{Pc}_{2}$ that not contain the trihalide ions $[78,79]$.

\subsection{Magnetic properties}

The magnetic susceptibility of the $\left[\mathrm{ZrPc}_{2}\right] \mathrm{IBr}_{2}$ complex was measured between 300 and $1.8 \mathrm{~K}$. The paramagnetic susceptibility was obtained by subtracting the temperature-independent diamagnetic contribution of the phthalocyaninato rings and the diamagnetic contribution of the closed shell $\left(\mathrm{d}^{0}\right) \mathrm{Zr}^{4+}$ cation. Both contributions were obtained by the measurement of the diamagnetic susceptibility of the unoxidized $\mathrm{ZrPc}_{2}$ complex, which is equal to $-5.76 \times 10^{-4} \mathrm{emu} \mathrm{mol}^{-1}$. The value of the diamagnetic contribution of the mixed trihalide $\mathrm{IBr}_{2}{ }^{-}$ion was calculated from Pascal's constants as a sum of twice that for $\operatorname{Br}\left(42.4 \times 10^{-6} \mathrm{emu} \mathrm{mol}^{-1}\right)$ and that for $\mathrm{I}^{-}(-50.6 \times$ $10^{-6} \mathrm{emu} \mathrm{mol}^{-1}$ ) [80-82]. The corrected paramagnetic susceptibility of one-electron oxidized $\left[\mathrm{ZrPc}_{2}\right] \mathrm{IBr}_{2}$ at $300 \mathrm{~K}$ is $\approx 1.162 \times 10^{-3} \mathrm{emu} \mathrm{mol}^{-1}$. This value corresponds to $\sim 0.96$ spins per molecule $(S=1 / 2, g \cong 2)$. The temperature dependence of the corrected magnetic susceptibility of $\left[\mathrm{ZrPc}_{2}\right] \mathrm{IBr}_{2}$ can be fit approximately by the Curie-Weiss law, $\chi_{\mathrm{M}}=C /(T-\Theta)$ with a Weiss constant $\Theta(\mathrm{K})$ of $\approx-3.7$ (see Fig. 5). The negative Weiss constant represents the antiferromagnetic coupling among unpaired electrons. The effective temperature-independent magnetic moment, calculated from the relationship $\mu_{\mathrm{eff}}=2.828\left(\chi_{\mathrm{M}} T\right)^{1 / 2}$, is

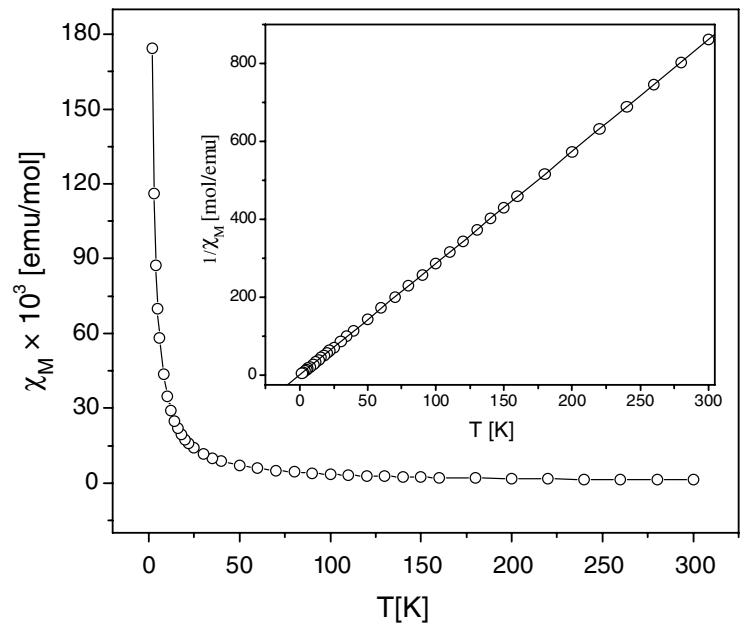

Fig. 5. Plots of the magnetic susceptibility $\left(\chi_{\mathrm{M}}\right)$ of the $\left[\mathrm{ZrPc}_{2}\right] \mathrm{IBr}_{2}$ solid sample vs. temperature. Inset: $1 / \chi_{M}$ vs. temperature.

equal to $\approx 1.67 \mu_{\mathrm{B}}$. This value is slightly lower than the spin-only magnetic moment $\left(\mu_{\text {spin-only }}=1.73 \mu_{\mathrm{B}}\right)$.

The EPR spectrum, measured on a solid polycrystalline sample of $\left[\mathrm{ZrPc}_{2}\right] \mathrm{IBr}_{2}$ at room temperature $\left(295^{\circ} \mathrm{C}\right)$, exhibits one narrow signal in the proximity of the free electron $g$ value. The $g$ value of 2.0025 and a line width $\Gamma=$ $6.5 \mathrm{G}$ indicate the formation of a ligand-centered $\pi$-radical. Integration of this signal results in $3.98 \times 10^{20} \mathrm{spins} / \mathrm{g}$, i.e. 0.927 spins per $\left[\mathrm{ZrPc}_{2}\right] \mathrm{IBr}_{2}$ molecule. The spin concentration obtained from the EPR measurements is in good agreement with that from magnetic susceptibility measurements. The EPR parameters, $g, \Gamma$ and spins concentration per molecule obtained for the $\left[\mathrm{ZrPc}_{2}\right] \mathrm{IBr}_{2}$ complex are quite similar to that observed for one-electron oxidized $\left[\mathrm{ZrPc}_{2}\right] \mathrm{I}_{3} \cdot \mathrm{I}_{2}$ [39]. Although the $g$ and $\Gamma$ parameters observed in the spectrum of the third partially oxidized zirconium diphthalocyaninato complex $\left[\mathrm{ZrPc}_{2}\right]\left(\mathrm{I}_{3}\right)_{2 / 3}$ are comparable, the spin concentration is significantly lower [38]. The difference in the spin concentrations between $\left[\mathrm{ZrPc}_{2}\right] \mathrm{IBr}_{2}$ and $\left[\mathrm{ZrPc}_{2}\right] \mathrm{I}_{3} \cdot \mathrm{I}_{2}$ - both one-electron oxidized and monoclinic and $\left[\mathrm{ZrPc}_{2}\right]\left(\mathrm{I}_{3}\right)_{2 / 3}$ (tetragonal) results from the difference in their crystal structures. In the tetragonal crystal of $\left[\mathrm{ZrPc}_{2}\right]\left(\mathrm{I}_{3}\right)_{2 / 3}$ the Pc ligands are closely planar and the interactions between $\mathrm{Pc}^{-}$radicals are more effective and decreases the spins concentration in relation to both monoclinic $\left[\mathrm{ZrPc}_{2}\right] \mathrm{IBr}_{2}$ and $\left[\mathrm{ZrPc}_{2}\right] \mathrm{I}_{3} \cdot \mathrm{I}_{2}$ crystals in which, due to the saucer shaped Pc rings, the interactions are less effective.

For $\left[\mathrm{ZrPc}_{2}\right] \mathrm{IBr}_{2}$ the $g$ value remains constant with decreasing temperature, but the line width decreases only slightly to a value of $5.4 \mathrm{G}$ at $80 \mathrm{~K}$, the lowest measurement temperature. The narrow line width of the EPR signal within the temperature range is typical for one-dimensional conductors because the direction of spin-lattice relaxation is restricted and slower [83]. The decrease of the line width can be explained in term of enhanced motional narrowing from a reduction in carrier mobility with decreasing temperature. 


\subsection{Single-crystal electrical conductivity of $\left[\mathrm{ZrPc}_{2}\right] \mathrm{IBr}_{2}$}

The single-crystal electrical conductivity along the stacking axis of one-electron oxidized $\left[\mathrm{ZrPc}_{2}\right]^{+}$units $(a$ axis, see Fig. 3a) at room temperature is equal to $4.6 \Omega^{-1} \mathrm{~cm}^{-1}$, while the conductivity measured along the $c$ and $b$ axes of the crystal is in the range $3.2-3.7 \times 10^{-3} \Omega^{-1} \mathrm{~cm}^{-1}$. The electrical conductivity of $\left[\mathrm{ZrPc}_{2}\right] \mathrm{IBr}_{2}$ is comparable to the conductivity of the second one-electron oxidized zirconium diphthalocyaninato complex $\left[\mathrm{ZrPc}_{2}\right] \mathrm{I}_{3} \cdot \mathrm{I}_{2}[39]$. The conductivity data of the third known, partially oxidized by iodine, zirconium diphthalocyanine $\left[\mathrm{ZrPc}_{2}\right]\left(\mathrm{I}_{3}\right)_{2 / 3}$ are available only for the polycrystalline compacted sample [38]. Therefore, the electrical conductivity of this $\left[\mathrm{ZrPc}_{2}\right] \mathrm{IBr}_{2}$ complex was also performed on a polycrystalline sample, for comparison. The conductivity measured on the polycrystalline sample of $\left[\mathrm{ZrPc}_{2}\right] \mathrm{IBr}_{2}$ pressed into pellets $\left(\sim 10^{5} \mathrm{kPa}\right)$ is equal to $6.5-7.2 \times 10^{-2} \Omega^{-1} \mathrm{~cm}^{-1}$, and is slightly greater than for the complex of $\left[\mathrm{ZrPc}_{2}\right]\left(\mathrm{I}_{3}\right)_{2 / 3}$ (see Table 6) [38]. The electrical conductivity measured on a polycrystalline sample of unoxidized $\mathrm{ZrPc}_{2}$ at room temperature shows typical values for isolators $\left(\sigma_{\mathrm{RT}}<10^{-9} \Omega^{-1} \mathrm{~cm}^{-1}\right)$.

The single-crystal conductivity of $\left[\mathrm{ZrPc}_{2}\right] \mathrm{IBr}_{2}$ along the stacks of $\left[\mathrm{ZrPc}_{2}\right]^{+}$units decreases with decreasing temperature (Fig. 6), thus the crystal exhibits non-metallic character in conductivity $(\mathrm{d} \sigma / \mathrm{d} T>0)$. Generally, non-metallic molecular conductors exhibit exponential temperature dependence of $\sigma_{(\mathrm{T})}$, because of the carrier density or mobility or both are activated. The temperature dependence of conductivity may be fitted to the expression $\sigma_{(\mathrm{T})}=\sigma_{0} \exp \left(-E_{\mathrm{a}} / k T\right)$, where $E_{\mathrm{a}}$ is the activation energy and $k$ is the Boltzman's constant. A least-squares fit to the data shows linear character of $\ln \left(\sigma_{(\mathrm{T})} / \sigma_{(\mathrm{RT})}\right)$ versus $1 / T$ (Fig. 6 ) and yields an activation energy of $0.025(2) \mathrm{eV}$. The relatively high room temperature conductivity of $\left[\mathrm{ZrPc}_{2}\right] \mathrm{IBr}_{2}$ along the stacking axis, but significantly lower in comparison to the conductivity of the best molecular conductor, i.e. iodine-doped nickel phthalocyanine $\operatorname{NiPcI}_{x}\left(\sigma_{(\mathrm{RT})} \approx 600 \Omega^{-1} \mathrm{~cm}^{-1}\right)^{3}$, can be explained by a significant overlap of the $\pi$-orbitals resulting from the staggered orientation of the Pc rings (rotation angle of the Pc rings equals $45.0(3)^{\circ}$ ) in the sandwich as well as between the sandwich within the stacks. This rotation of $\mathrm{Pc}$ rings makes eight short inter-ring contacts between the pyrrole $\alpha$-carbon atoms (the inter-ring $\mathrm{C}_{\alpha}-\mathrm{C}_{\alpha}$ contacts

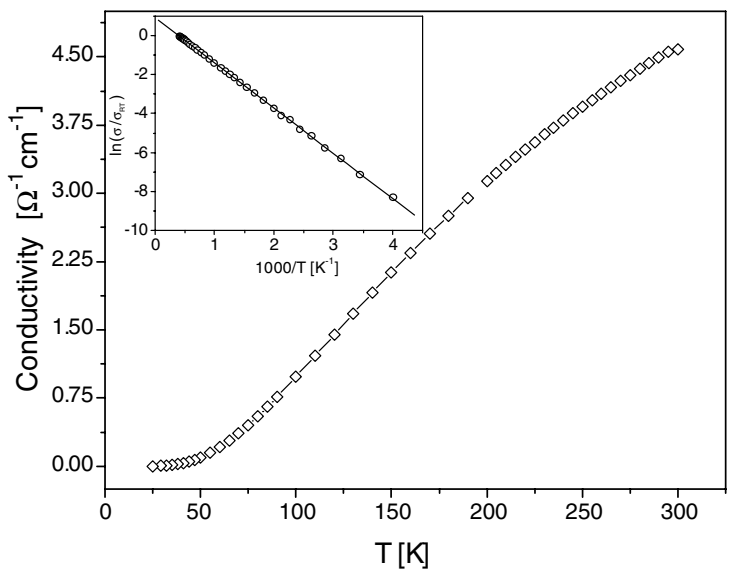

Fig. 6. Temperature dependence of the conductivity of $\left[\mathrm{ZrPc}_{2}\right] \mathrm{IBr}_{2}$ (single crystal) measured along the stacks of $\left[\mathrm{ZrPc}_{2}\right]^{+}$units. Inset: plot of $\ln \left(\sigma / \sigma_{\mathrm{RT}}\right)$ vs. $1000 / T$.

range from 2.858(3) (C9-C28) to 3.017(3) $\AA$ (C8-C21)). The theoretical calculation shows that these carbon atoms make appreciable contributions to the partially occupied HOMO $\pi$-molecular orbital of the phthalocyaninato macrocycle and due to the relatively short contacts provide the greatest overlap of the HOMO $\pi$-molecular orbital of Pc that forms the conduction band of the partially oxidized molecular crystals $[84,85]$. These data clearly show that charge propagation mainly proceeds along the one-dimensional stacks of $\left[\mathrm{ZrPc}_{2}\right]^{+}$moieties. Each $\left[\mathrm{ZrPc}_{2}\right]^{+}$unit with the closed shell $\left(\mathrm{d}^{0}\right) \mathrm{Zr}^{4+}$ cation contains the $\mathrm{Pc}^{2-}$ and one-electron oxidized $\mathrm{Pc}^{-\cdot} \pi$-radical ligands. During the charge transport there is no need for a change of the population distribution among the sites because the jumping of the electron from one side to another with the pre-formed hole takes place between isoenergetic configurations (see Scheme 2a). This is consistent with the relatively small activation energy of $0.025(2) \mathrm{eV}$, obtained by a fit of the conductivity data, compared with the activation energy of other one-dimensional iodine-doped molecular conductors [54]. The charge transport in the non-oxidized $\mathrm{ZrPc}_{2}$ sample requires a large activation energy for carrier creation, since this involves high energy of states creating and separating the positive and negative (oxidized and reduced) $\left[\mathrm{ZrPc}_{2}\right]^{+}$ and $\left[\mathrm{ZrPc}_{2}\right]^{-}$ions along the chains (see Scheme $2 \mathrm{~b}$ ). Thus the activation energy is compared to the sum of the energies

Table 6

EPR and electrical conductivity data (room temperature) of zirconium diphthalocyaninato complexes

\begin{tabular}{|c|c|c|c|c|c|c|c|}
\hline \multirow[t]{2}{*}{ Compound } & \multirow[t]{2}{*}{$g$} & \multirow[t]{2}{*}{$\Gamma$} & \multicolumn{2}{|c|}{ Unpaired electron per molecule } & \multicolumn{2}{|c|}{ Conductivity, $\sigma_{\mathrm{RT}}\left(\Omega^{-1} \mathrm{~cm}^{-1}\right)$} & \multirow[t]{2}{*}{ Ref. } \\
\hline & & & From EPR & Theoretical value & Single crystal ${ }^{\mathrm{a}}$ & Powder $^{\mathrm{b}}$ & \\
\hline$\left[\mathrm{ZrPc}_{2}\right] \mathrm{IBr}_{2}$ & 2.0025 & 6.5 & 0.927 & 1 & 4.6 & $6.5-7.4 \times 10^{-2}$ & this work \\
\hline$\left[\mathrm{ZrPc}_{2}\right] \mathrm{I}_{3} \cdot \mathrm{I}_{2}$ & 2.0026 & 6.2 & 0.920 & 1 & 3.8 & $5.5-6.2 \times 10^{-2}$ & {$[39]$} \\
\hline $\begin{array}{l}{\left[\mathrm{ZrPc}_{2}\right]\left(\mathrm{I}_{3}\right)_{2 / 3}} \\
\mathrm{ZrPc}_{2}{ }^{\mathrm{d}}\end{array}$ & 2.0026 & 6.6 & 0.185 & 0.3333 & $\sim 3.5-3.8^{\mathrm{c}}$ & $\begin{array}{l}5.2-5.5 \times 10^{-2} \\
<10^{-9}\end{array}$ & $\begin{array}{l}{[38]} \\
\text { this work }\end{array}$ \\
\hline
\end{tabular}

\footnotetext{
a Along the stacks.

${ }^{\mathrm{b}}$ On the polycrystalline compacted sample.

${ }^{c}$ From correlation between conductivity on single crystal and pressed powder.

${ }^{\mathrm{d}}$ EPR not active.
} 
a
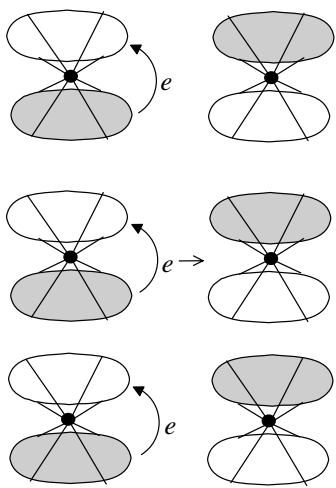

$\left[\mathrm{ZrPc}_{2}\right] \mathrm{IBr}_{2}$ b
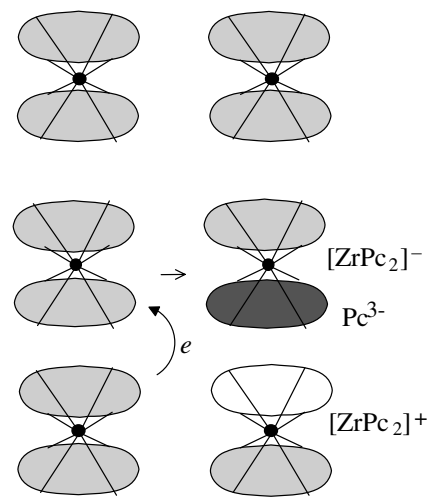

$\left[\mathrm{ZrPc}_{2}\right]$ where: $\bigcirc=\mathrm{Pc}^{2-} ; \bigcirc=\mathrm{Pc}^{-} ; \quad=\mathrm{Pc}^{3-} \bullet=\mathrm{Zr}^{4+}$

Scheme 2. Schematic representation of the charge propagation along the $\left\{\left[\mathrm{ZrPc}_{2}\right]^{+}\right\}_{n}$ stacks.

that are related to the one-electron oxidation and the oneelectron reduction of the $\mathrm{ZrPc}_{2}$ complex, i.e. the formation of $\left[\mathrm{ZrPc}_{2}\right]^{+}$and $\left[\mathrm{ZrPc}_{2}\right]^{-}$ions. The first oxidation and first reduction peaks obtained by cyclic voltammetry for $\mathrm{ZrPc}_{2}$ are observed at $+1.2 \mathrm{~V}$ and $-1.4 \mathrm{~V}$, respectively [50]. The charge transport in the tetragonal complex $\left[\mathrm{ZrPc}_{2}\right]\left(\mathrm{I}_{3}\right)_{2 / 3}$, in which the formal oxidation state of the $\left[\mathrm{ZrPc}_{2}\right]$ units is equal to $+2 / 3$, is less effective, since statistically one $\left[\mathrm{ZrPc}_{2}\right]$ unit per three contains two $\mathrm{Pc}^{2-}$ ligands $\left(\left[\mathrm{ZrPc}^{2-} \mathrm{Pc}^{2-}\right]-\right.$ $\left.\left[\mathrm{ZrPc}^{2-} \mathrm{Pc}^{-*}\right]\left[\mathrm{ZrPc}^{2-} \mathrm{Pc}^{-\cdot}\right]\left(\mathrm{I}_{3}\right)_{2}\right)$, so the charge transport, i.e. the jumping of the electron with a pre-formed hole, is broken.

\section{Conclusions}

The investigation of doped metallodiphthalocyaninato complexes was undertaken with the dual goals of developing new controls over the structures of mono-dimensional electrically conductive molecular materials as well as investigating the dependence of the conductivity on the formal partial oxidation state of the phthalocyaninato rings in the sandwich $\mathrm{MPc}_{2}$ system and on the nature of the anionic part of the sandwich complexes $\left[\mathrm{MPc}_{2}\right] \mathrm{X}$, where $\mathrm{X}=\mathrm{I}_{3}{ }^{-}$, $\mathrm{IBr}_{2}{ }^{-}$or $\left(\mathrm{I}_{3}{ }^{-} \cdot \mathrm{I}_{2}\right)$. The present study of $\left[\mathrm{ZrPc}_{2}\right] \mathrm{IBr}_{2}$ and our earlier results related to two other iodine-doped zirconium diphthalocyaninato complexes, partially oxidized $\left[\mathrm{ZrPc}_{2}\right]\left(\mathrm{I}_{3}\right)_{2 / 3}$ and one-electron oxidized $\left[\mathrm{ZrPc}_{2}\right] \mathrm{I}_{3} \cdot \mathrm{I}_{2}$, shed new light on the properties of both types of doped materials. Upon one electron oxidation the $\mathrm{ZrPc}_{2}$ complex is converted to an architecture with staggered rings (rotation angle of $45^{\circ}$ in both one-electron oxidized complexes: $\left[\mathrm{ZrPc}_{2}\right] \mathrm{IBr}_{2}$ and $\left.\left[\mathrm{ZrPc}_{2}\right] \mathrm{I}_{3} \cdot \mathrm{I}_{2}\right)$, regardless of the interplanar $\mathrm{Pc}-\mathrm{Pc}$ spacing. The driving force for this conformation change are the net "bonding" overlaps between the $\pi$-electron macrocyclic rings. Concerning the relationship between the interplanar spacing in the one-electron oxi- dized $\left[\mathrm{ZrPc}_{2}\right]^{+}$units and charge transfer properties, the following can be concluded: decreasing interplanar separation results in increasing charge transfer. Although the electrical conductivities in the stacking direction of the third complex of $\left[\mathrm{ZrPc}_{2}\right]\left(\mathrm{I}_{3}\right)_{2 / 3}$ with a non-integral oxidation state of sandwiched $\left[\mathrm{ZrPc}_{2}\right]^{2 / 3+}$ units are not available, established empirical correlation between single crystal and pressed powder data (Table 6) afford a reasonable estimation of the value and allow a qualitative comparison with both one-electron oxidized zirconium diphthalocyaninato complexes.

The EPR measurement shows significantly lower 'unpaired' spins in the tetragonal partially oxidized complex of $\left[\mathrm{ZrPc}_{2}\right]\left(\mathrm{I}_{3}\right)_{2 / 3}$, in which both $\mathrm{Pc}$ rings are closely planar, resulting in increased $\pi$-orbital overlap. In both one-electron oxidized zirconium diphthalocyaninato complexes the concentration of the 'unpaired' spins are comparable, however, on looking at these results it can be told that in $\left[\mathrm{ZrPc}_{2}\right] \mathrm{IBr}_{2}$ the 'unpaired' electrons as well as the conductivity are slightly greater than for $\left[\mathrm{ZrPc}_{2}\right] \mathrm{I}_{3} \cdot \mathrm{I}_{2}$ (see Table 6), which correlate well with the interplanar Pc-Pc distance (2.434(3) $\AA$ in $\left[\mathrm{ZrPc}_{2}\right] \mathrm{IBr}_{2}$ and 2.493(3) $\AA$ in $\left.\left[\mathrm{ZrPc}_{2}\right] \mathrm{I}_{3} \cdot \mathrm{I}_{2}\right)$. The decreasing of the EPR line width $(\Gamma)$ in $\left[\mathrm{ZrPc}_{2}\right] \mathrm{IBr}_{2}$ was interpreted in the terms of reduction in carrier mobility with decreasing temperature which correlates well with the temperature dependence of single-crystal conductivity.

\section{Acknowledgment}

G.J. Perpétuo thanks the CNPq foundation (Brazil) for the scholarship.

\section{Appendix A. Supplementary data}

Crystallographic data for the structure reported in this paper have been deposited with the Cambridge Crystallographic Database as Supplementary Publication No. CCDC-606662. Copies of the data can be obtained free of charge on application to The Director, CCDC, 12 Union Road, Cambridge CB2 1EZ, UK (fax: +44 1223 336033; email: deposit@ccdc.cam.ac.uk or http://www.ccdc.cam. ac.uk). Supplementary data associated with this article can be found, in the online version, at doi:10.1016/ j.poly.2006.06.020.

\section{References}

[1] J.L. Petersen, C.J. Schramm, D.R. Stojakovic, B.M. Hoffman, T.J. Marks, J. Am. Chem. Soc. 99 (1977) 286.

[2] C.J. Schramm, D.R. Stojakovic, B.M. Hoffman, T.J. Marks, Science 200 (1978) 47

[3] C.J. Schramm, R.P. Scaringe, D.R. Stojakovic, B.M. Hoffman, J.A. Ibers, T.J. Marks, J. Am. Chem. Soc. 102 (1980) 6702.

[4] J.A. Ibers, L.J. Pace, J. Martinsen, B.M. Hoffman, Struct. Bond. (Berlin) 50 (1982) 1

[5] J. Martinsen, R.L. Greene, S.M. Palmer, B.M. Hoffman, J. Am. Chem. Soc. 105 (1983) 677.

[6] B.M. Hoffman, J.A. Ibers, Acc. Chem. Res. 16 (1983) 15 
[7] T.E. Phillips, R.P. Scaringe, B.M. Hoffman, J.A. Ibers, J. Am. Chem. Soc. $102(1980) 3435$.

[8] J. Martinsen, L.J. Pace, T.E. Phillips, B.M. Hoffman, J.A. Ibers, J. Am. Chem. Soc. 104 (1982) 83.

[9] J. Martinsen, J. Tanaka, R.L. Greene, B.M. Hoffman, Phys. Rev. B: Condens. Matter 30 (1984) 6296.

[10] S.M. Palmer, M.Y. Ogawa, J. Martinsen, J.L. Stanton, B.M. Hoffman, J.A. Ibers, R.L. Greene, Mol. Cryst. Liq. Cryst. 120 (1985) 427.

[11] T.J. Marks, Science 227 (1985) 881.

[12] T.J. Marks, Angew. Chem., Int. Ed. Engl. 29 (1990) 857.

[13] K. Liou, M.Y. Ogawa, T.P. Newcomb, G. Quirion, M. Lec, M. Poirier, W.P. Halperin, B.M. Hoffman, J.A. Ibers, Inorg. Chem. 28 (1989) 3889.

[14] D.C. Miller, J.C. Bollinger, B.M. Hoffman, J.A. Ibers, Inorg. Chem. 33 (1994) 3354.

[15] H. Hasegawa, T. Naito, T. Inabe, T. Akutangawa, T. Nakamura, J. Mater. Chem. 8 (1998) 1567.

[16] J.M. Williams, J.A. Schultz, A.E. Underhill, K. Carneiro, in: J.S Miller (Ed.), Extended Linear Chain Compounds, vol. 3, Plenum Press, New York, 1983, pp. 73-118.

[17] M.C. Bohm, One Dimensional Organometallic Materials, Lecture Notes in Chemistry, vol. 48, Springer, Berlin, 1987.

[18] B.M. Hoffman, J. Martinsen, L.J. Pace, J.A. Ibers, in: J.S. Miller (Ed.), Extended Linear Chain Compounds, vol. 3, Plenum Press, New York, 1983, pp. 459-549.

[19] R.C. Teitelbaum, S.L. Ruby, T.J. Marks, J. Am. Chem. Soc. 100 (1978) 3215.

[20] R.C. Teitelbaum, S.L. Ruby, T.J. Marks, J. Am. Chem. Soc. 102 (1980) 3222.

[21] R.P. Scaringe, J.A. Ibers, Acta Crystallogr. A35 (1979) 803.

[22] M. Cowie, A. Gleizes, G.W. Grynkiewich, D.W. Kalina, M.S. McClure, R.P. Scaringe, R.C. Teitebaum, S.L. Ruby, J.A. Ibers, C.R. Kannewurf, J. Am. Chem. Soc. 101 (1979) 2921

[23] M. Mizuno, J. Tanaka, I. Harada, J. Phys. Chem. 85 (1981) 1789.

[24] J. Martinsen, J.L. Stanton, R.L. Greene, J. Tanaka, B.M. Hoffman, J.A. Ibers, J. Am. Chem. Soc. 107 (1985) 6915.

[25] M.Y. Ogawa, J. Martinsen, S.M. Palmer, J.L. Stanton, J. Tanaka, R.L. Greene, B.M. Hoffman, J.A. Ibers, J. Am. Chem. Soc. 109 (1987) 1115

[26] R. Kubiak, J. Janczak, Cryst. Res. Technol. 36 (2001) 1095.

[27] M. Moussavi, A. DeCian, J. Fischer, R. Weiss, Inorg. Chem. 27 (1988) 1287.

[28] A. Darovsky, L.Y. Wu, P. Lee, H.S. Shen, Acta Crystallogr. C47 (1991) 1836.

[29] D. Chabach, M. Lachbar, A. DeCian, J. Fischer, R. Weiss, New J. Chem. 16 (1992) 431.

[30] A. Darovsky, V. Keserashvili, R. Harlow, I. Mutikainen, Acta Crystallogr. B50 (1994) 582.

[31] G. Ostendorph, J.P. Werner, H. Homborg, Acta Crystallogr. C51 (1995) 1125.

[32] J. Janczak, R. Kubiak, A. Jezierski, Inorg. Chem. 34 (1995) 3505.

[33] A. Copabianchi, C. Ercolani, A.M. Paoletti, G. Pennesi, G. Rossi, A Chiesi-Villa, C. Rizzoli, Inorg. Chem. 32 (1993) 4605.

[34] J. Janczak, R. Kubiak, F. Hahn, Inorg. Chim. Acta 281 (1998) 195.

[35] J. Janczak, R. Kubiak, Polyhedron 18 (1999) 1621.

[36] J. Janczak, R. Kubiak, A. Jezierski, Inorg. Chem. 38 (1999) 2043.

[37] J. Janczak, R. Kubiak, I. Svoboda, A. Jezierski, H. Fuess, Inorg. Chim. Acta 304 (2000) 150.

[38] J. Janczak, Y.M. Idemori, Inorg. Chim. Acta 325 (2001) 85.

[39] J. Janczak, Inorg. Chem. 42 (2003) 3549.

[40] R. Kubiak, J. Janczak, J. Alloys Compd. 200 (1993) L7.

[41] J. Silver, J.P. Lukes, S.D. Howe, B. Howlin, J. Mater. Chem. 1 (1991) 29.

[42] KUMA Diffraction, KUMA KM-4 CCD Program Package, Ver. 163, Wrocław, Poland, 2000.

[43] G.M. Sheldrick, shelXtl Program, Siemens Analytical X-ray Instrument Inc., Madison, WI, 1991.

[44] G.M. Sheldrick, SHELXL-97, Program for the Solution and Refinement of Crystal Structures, University of Göttingen, Göttingen, Germany, 1997.
[45] T.E. Phillips, J.R. Anderson, C.J. Schramm, B.M. Hoffman, Rev. Sci. Instrum. 50 (1979) 263.

[46] T. Inabe, T.J. Marks, R.L. Burton, J.W. Lyding, W.J. McCarthy, C.R. Kannewurf, G.M. Reisner, F.H. Herbstein, Solid State Commun. 54 (1985) 501.

[47] N.N. Greenwood, A. Earnshaw, Chemistry of the Elements, Pergamon Press, New York, 1989.

[48] G.A. Landrum, N. Goldberg, R. Hoffmann, J. Chem. Soc., Dalton Trans. (1997) 3605.

[49] A.I. Popov, R.E. Buckles, in: T. Moeller (Ed.), Inorganic Syntheses, vol. V, McGraw-Hill Book Co. Inc., New York, 1957, pp. 167-175.

[50] J. Silver, P.J. Lukes, P.K. Hey, J.M. O'Connor, Polyhedron 8 (1989) 1631.

[51] J. Janczak, Polish J. Chem. 74 (2000) 157.

[52] J.R. Ferraro, M.A. Beno, R.J. Thorn, H.H. Wang, K.S. Webb, J.M. Williams, J. Phys. Chem. Solids 47 (1986) 301.

[53] D.W. Kalina, J.W. Lyding, M.T. Ratajack, C.R. Kannewurf, T.J. Marks, J. Am. Chem. Soc. 102 (1983) 7854.

[54] B.N. Diel, T. Inabe, J.W. Lyding, K.F. Schoch Jr., C.R. Kannewurf, T.J. Marks, J. Am. Chem. Soc. 105 (1985) 1551.

[55] W. Kiefer, Appl. Spectrosc. 28 (1974) 115.

[56] W.E. Bennett, D.E. Broberg, N.C. Baenziger, Inorg. Chem. 12 (1973) 930.

[57] J. Janczak, R. Kubiak, J. Alloys Compd. 204 (1994) 5.

[58] A. DeCian, M. Moussavi, J. Fischer, R. Weiss, Inorg. Chem. 24 (1985) 3162.

[59] C. Ercolani, A.M. Paoletti, G. Pennesi, G. Rossi, A. Chiesi-Villa, C. Rizzoli, J. Chem. Soc., Dalton Trans. (1990) 1971.

[60] J. Janczak, R. Kubiak, Polyhedron 22 (2003) 313.

[61] A. Gieren, W. Hoppe, J. Chem. Soc., Chem. Commun. (1971) 413.

[62] R.D. Shannon, Acta Crystallogr. A32 (1967) 751.

[63] W.A. Nevin, W. Liu, A.B.P. Lever, Can. J. Chem. 65 (1987) 855.

[64] D.S. Terekhov, K.J.M. Noaln, C.R. MaArthur, C.C. Leznoff, J. Org. Chem. 61 (1996) 3034.

[65] H. Isago, D.S. Terekhov, C.C. Leznoff, J. Porphyr. Phthalocya. 1 (1997) 135.

[66] H. Isago, C.C. Leznoff, M.F. Ryan, R.A. Metcalfe, R. Davis, A.B.P. Lever, Bull. Chem. Soc. Jpn. 71 (1998) 1039.

[67] L. Pauling, The Nature of the Chemical Bond, 3rd ed., Cornell University Press, Ithaca, 1960, p. 262.

[68] A.S. Gardberg, S. Yang, B.M. Hoffman, J.A. Ibers, Inorg. Chem. 41 (2002) 1778.

[69] T. Naito, A. Tateno, T. Udagawa, H. Kobayashi, R. Kato, A. Kobayashi, T. Nagami, J. Chem. Soc., Faraday Trans. 90 (1994) 763.

[70] F.H. Allen, O. Kennard, Chem. Des. Autom. News 27 (1993) 303.

[71] A. Henrikson, B. Roos, R. Sundon, Theor. Chim. Acta 27 (1972) 303.

[72] L.K. Lee, N.H. Sabelli, P.R. Leberton, J. Phys. Chem. 86 (1982) 3926.

[73] H. Shiari, H. Tsuiki, E. Masuda, T. Koyama, K. Hanabusa, N. Kobayashi, J. Phys. Chem. 95 (1991) 417.

[74] K. Takahashi, Y. Tomita, Y. Harada, K. Tsubota, M. Honda, K. Kasuga, K. Sogabe, T. Tokii, Chem. Lett. (1992) 759.

[75] N. Ishikawa, Y. Kaizu, J. Phys. Chem. 100 (1996) 8722.

[76] K. Takahashi, Y. Tomita, Y. Harada, K. Tsubota, M. Honda, K. Kasuga, K. Sogabe, T. Tokii, Chem. Lett. (1998) 173.

[77] W. Gabes, D.J. Stufkens, Spectrochim. Acta Part A 30 (1974) 1835.

[78] E. Orti, J.E. Bredas, C. Clarisse, J. Chem. Phys. 92 (1990) 1228.

[79] J. Janczak, Polish J. Chem. 72 (1998) 1871.

[80] L.N. Mulay, in: L.N. Mulay, E.A. Brodeaux (Eds.), Theory and Applications of Molecular Diamagnetism, Wiley Interscience, New York, 1976 (Chapter 5.3).

[81] J.C. Bonner, M.E. Fischer, Phys. Rev. A 135 (1964) 640.

[82] A.J. Epstein, H. Rommelmann, M.A. Druy, A.J. Heegaer, A.G. MacDiarmid, Solid State Commun. 38 (1981) 683.

[83] K. Murata, K. Liou, J.A. Thompson, E.M. McGhee, D.E. Rende, D.E. Ellis, R.L. Musselman, B.M. Hoffman, J.A. Ibers, Inorg. Chem. 36 (1997) 3363.

[84] L.J. Pace, J. Martinsen, A. Ulman, B.M. Hoffman, J.A. Ibers, J. Am. Chem. Soc. 105 (1983) 2612.

[85] W.J. Pietro, T.J. Marks, M.A. Ratner, J. Am. Chem. Soc. 107 (1985) 5387. 